\title{
Use of Dual-wavelength Radar for Snow Parameter Estimates
}

\author{
Liang Liao \\ Goddard Earth Sciences and Technology/Caelum, NASA/GSFC, Greenbelt, MD 20771 \\ Robert Meneghini \\ Code 975, NASA/GSFC, Greenbelt, MD 20771 \\ Toshio Iguchi \\ Communications Research Laboratory, Tokyo 184-8795, Japan \\ Andrew Detwiler \\ South Dakota School of Mines \& Technology, Rapid City, SD 57701
}

Submitted to

Journal of Atmospheric and Oceanic Technology

Revised in February 2005

Corresponding author information:

Dr. Liang Liao

Goddard Earth Science Technology/Caelum Research Corp.

Code 975

NASA/Goddard Space Flight Center

Greenbelt, MD 20771

301-614-5718 (phone)

301-614-5558 (fax)

Email:1liao@priam.gsfc.nasa.gov 


\begin{abstract}
Use of dual-wavelength radar, with properly chosen wavelengths, will significantly lessen the ambiguities in the retrieval of microphysical properties of hydrometeors. In this paper, a dual-wavelength algorithm is described to estimate the characteristic parameters of the snow size distributions. An analysis of the computational results, made at $\mathrm{X}$ and $\mathrm{Ka}$ bands (T-39 airborne radar) and at $\mathrm{S}$ and $\mathrm{X}$ bands (CP-2 ground-based radar), indicates that valid estimates of the median volume diameter of snow particles, $\mathrm{D}_{0}$, should be possible if one of the two wavelengths of the radar operates in the nonRayleigh scattering region. However, the accuracy may be affected to some extent if the shape factors of the Gamma function used for describing the particle distribution are chosen far from the true values or if cloud water attenuation is significant. To examine the validity and accuracy of the dual-wavelength radar algorithms, the algorithms are applied to the data taken from the Convective and Precipitation-Electrification Experiment (CaPE) in 1991, in which the dual-wavelength airborne radar was coordinated with in situ aircraft particle observations and ground-based radar measurements. Having carefully co-registered the data obtained from the different platforms, the airborne radar-derived size distributions are then compared with the in-situ measurements and ground-based radar. Good agreement is found for these comparisons despite the uncertainties resulting from mismatches of the sample volumes among the different sensors as well as spatial and temporal offsets.
\end{abstract}




\section{INTRODUCTION}

Radar has been considered as an effective tool for remotely measuring different types of precipitation. Directly relating a radar measurable such as the radar reflectivity factor, $\mathrm{Z}$, to the precipitation rate, $\mathrm{R}$, is widely used to monitor and estimate the development of a variety of storms. Sekhon and Srivastava (1970) carefully examined the measured snow size distributions reported by Imai et al. (1955), Magono (1957) and Ohtake (1968), and proposed equations that connect the radar reflectivity to the snow rate in the form of melted water, the median volume diameter and the liquid water content. Their approach, among others (e.g., Smith 1984; Loffler-Mang and Blahak 2001), uses a single wavelength much larger than the particle sizes so that Rayleigh scattering is appropriate for their analysis. However, in view of the complexity of snow in nature, a single wavelength radar measurement is unable to account fully for the variability arising from different meteorological conditions. As such, it is not surprising to see the existence of many Z-R relations reported in the literatures (see Gunn and Marshall 1958; Carlson and Marshall 1972; Smith 1984; Boucher and Wieler 1985; Matrosov 1992).

Dual-wavelength radar techniques have shown promise in accurately estimating characteristics of the size distribution when one or both wavelengths operate in the nonRayleigh region (Matrosov 1992 and 1998; Meneghini et al 1992, 1994 and 1997; Liao et al. 1997; Vivekanandan et al. 2001; Mardiana et al. 2004). A spaceborne radar operating at $\mathrm{Ku}$ and $\mathrm{Ka}$ bands has been proposed as one of the core instruments for the Global Precipitation Measurements (GPM) (Iguchi et al. 2002) and will serve as a calibrator for other instruments aboard the GPM satellite in mapping precipitation globally. With use of dual-wavelength radar, the ambiguities are significantly lessened for the retrieval of the 
microphysical properties of hydrometeors in comparison with single wavelength radars such as the TRMM Precipitation Radar (PR) (Simpson et al. 1996). In this paper we begin with a discussion of a dual-wavelength algorithm by which the snow particle size distribution can be inferred. In an effort to examine its validity and accuracy, two separate cases from the Convective and Precipitation-Electrification Experiment (CaPE) in 1991 are studied. The algorithm is applied to measurements taken by a dualwavelength ( $\mathrm{X}$ and $\mathrm{Ka}$ bands) airborne radar. The retrieved results of the snow particle size distributions are then compared with those from in-situ aircraft measurements and the NCAR CP-2 S- and X-band ground-based radars that were coordinated with the airborne radar measurements. Good agreement is found for these comparisons despite spatial and temporal offsets as well as the uncertainties resulting from mismatches of the sample volumes among the different sensors.

\section{DUAL-WAVELENGTH ALGORITHM}

The effective radar reflectivity factor of the hydrometeors at wavelength $\lambda$ is given as

$$
Z_{e}=\frac{\lambda^{4}}{\pi^{5}\left|K_{w}\right|^{2}} \int_{0}^{\infty} N(D) \sigma_{b}(D, \lambda) d D
$$

where the $N(D)$ is the particle size distribution and $\sigma_{b}(D, \lambda)$ the backscattering cross section. $K_{w}$, the dielectric factor, is used to designate $\left(m^{2}-1\right) /\left(m^{2}+2\right)$, where $m$ is the complex refractive index of water. By convention, $\left|\mathrm{K}_{\mathrm{w}}\right|^{2}$ is taken to be 0.93 (Battan 1973). While $Z_{e}$ can be converted from the radar return signals, $\sigma_{b}(D, \lambda)$ is directly computed by Mie theory. Finding a solution to the parameters of the N(D) from (1) is an inverse 
problem, and the focus of this paper. A more detail description of the dual-wavelength radar algorithm for the retrieval of $N(D)$ will be discussed below.

Based on measurements and model studies (Braham, 1990; Gorgucci et al. 2001, 2002; Bringi et al. 2002) the hydrometeor size distributions can be conveniently described by the Gamma distribution. A form of the Gamma size distribution of N(D), used widely in the retrieval of the microphysical properties of hydrometeors, is expressed as

$$
N(D)=N_{0} D^{\mu} \exp \left[-(3.67+\mu) \frac{D}{D_{0}}\right]
$$

where $\mathrm{N}_{0}$ is a parameter related to the hydrometeor number density, $\mathrm{D}$ the snow diameter, $\mathrm{D}_{0}$ the median volume diameter of the snow particle and $\mu$ the shape factor. The number concentration, $\mathrm{N}_{\mathrm{T}}$, can be expressed in terms of these variables by:

$$
\begin{aligned}
& N_{T}=N_{0} \Gamma(\mu+1) / G^{\mu+1}, \\
& G=(3.67+\mu) / D_{0},
\end{aligned}
$$

where $\Gamma$ is the Gamma function. The radar dual-frequency ratio (DFR) in $d B$, describing the difference of the radar reflectivity at 2 wavelengths, is defined as

$$
D F R=10 \log \left(Z_{u} / Z_{v}\right)
$$

where $Z_{u}$ and $Z_{v}$ are the radar reflectivity factors at wavelengths of $\lambda_{u}$ and $\lambda_{v}$. In this paper $\lambda_{u}$ is associated with the longer wavelength (lower frequency). The DFR is independent of the $\mathrm{N}_{0}$ as can be inferred from (1), (2) and (5). Matrosov (1992 and 1998) was the first to recognize that for constant snow densities, the DFR and $D_{0}$ relationships are nearly independent of snow density. 
Snow is a mixture of ice and air. Its effective dielectric constant, which is needed in the computation of $\sigma_{\mathrm{b}}(\mathrm{D}, \lambda)$ of $(1)$, is solely determined by the snow density (MaxwellGarnett 1904; Debye 1929; Bruggeman 1935; Meneghini and Liao 1996, 2000; Liao and Meneghini 2000). Thus the radar reflectivity factor is also a function of the snow density. Given a $D_{0}$ the ratio of $Z_{u}$ and $Z_{v}$ can be computed from (1) and (2) if $\mu$ is fixed, and subsequently DFR is determined based on (5). Figures 1 and 2 show the computational results of the DFR versus $D_{0}$ for the snow size distribution given by (2) for the T-39 airborne radar that operates at $\mathrm{X}$ and $\mathrm{Ka}$ bands. To see how the snow density affects the results of the DFR- $D_{0}$ relations, the computations are made for several snow densities ranging from 0.05 to $0.8 \mathrm{~g} / \mathrm{cm}^{3}$. The results depicted in Fig. 1 are for the case where $\mu$ equals 2. It is clearly seen that the relations between the DFR and $D_{0}$ are almost independent of the snow density for the $D_{0}$ less than $3.5 \mathrm{~mm}$. These are consistent with the findings reported by Matrosov (1992 and 1998). Moreover, the DFR has one-to-one correspondence with $D_{0}$, which means that (5) has a unique solution for $D_{0}$ for a given DFR. The increase of DFR with $\mathrm{D}_{0}$ can be attributed to the differences of the scattering characteristics between the approximately Rayleigh scattering at $\mathrm{X}$ band and nonRayleigh scattering at $\mathrm{Ka}$ band. The independence of the DFR- $\mathrm{D}_{0}$ relations on snow density is significant because the estimates of $D_{0}$ will not be affected by variations or inaccurate assumptions regarding snow density. This represents an advantage of dualwavelength radar technique in deriving snow parameters over the single wavelength radar method in which the snow density has to be assumed.

In Fig.2, the dependence of the DFR- $D_{0}$ relations on the parameter, $\mu$, is shown for a fixed snow density of $0.2 \mathrm{~g} / \mathrm{cm}^{3}$ as $\mu$ varies from -0.5 to 6 . The results show that for a 
fixed DFR, $D_{0}$ increases with $\mu$. While changes in the DFR- $D_{0}$ relations appear relatively large as $\mu$ changes from 0 to 4 , the differences in the DFR- $D_{0}$ relations change more gradually as $\mu$ increases from 4 to 8 . Dependence of the DFR- $D_{0}$ relations on $\mu$ may lead to an ambiguity in the estimate of $D_{0}$ if the values of $\mu$ fluctuate to a large degree. For example, a DFR of $5 \mathrm{~dB}$ corresponds to $\mathrm{D}_{0}$ values of $1.99,2.55$ and $2.75 \mathrm{~mm}$ for $\mu$ of 0,4 and 8 , respectively.

To analyze the ground-based CP-2 radar data, the results of the DFR versus $D_{0}$ are plotted in Figs. 3 and 4 for the case of $S$ and $\mathrm{X}$ bands. As the majority of snow particles are close to the Rayleigh scattering regime at $\mathrm{S}$ and $\mathrm{X}$ bands, where the radar reflectivity is independent of the wavelength, the DFR shown in Figs. 3 and 4 is typically less than 1 $\mathrm{dBZ}$ for $\mathrm{D}_{0}$ up to $3 \mathrm{~mm}$. The DFR- $\mathrm{D}_{0}$ relations for the $S$ and $\mathrm{X}$ bands depend on snow density (Fig.3) and $\mu$ (Fig.4). Because of the small dynamic range of DFR a small fluctuation in the measurement of this quantity can lead to a large error in $\mathrm{D}_{0}$. For example, an error of $0.2 \mathrm{dBZ}$ in the DFR generally translates into a difference of about $0.5 \mathrm{~mm}$ of $D_{0}$ for a $D_{0}$ near $1.5 \mathrm{~mm}$. This error is even greater for smaller values of $D_{0}$. Because of this, a large number of radar samples is needed to extract the signals in order to obtain reliable retrievals of $D_{0}$ from the $S$ and $X$ band radar. Although collecting a large number of samples poses a difficulty for air/space-borne radar systems, it is less of a problem for ground-based radars when pointed along a fixed direction or operated in a slow-scan mode. In view of the differences of the DFR- $\mathrm{D}_{0}$ relations between the T-39 and CP-2 radars, as depicted in Figs.1-4, wavelengths of $\mathrm{X}$ and $\mathrm{Ka}$ bands have a great advantage over a radar operating at $S$ and $X$ band in terms of stability and accuracy of 
snow parameter estimates as long as attenuation from rain or cloud water can be neglected.

For the snow region in stratiform precipitation where the attenuation is usually negligible for airborne $\mathrm{X}$ and $\mathrm{Ka}$ band frequencies, $\mathrm{D}_{0}$ can be directly estimated from the measured DFR. For ground radar, by contrast, the measured DFR in the snow region ususally needs to be corrected to account for attenuation of the signal through the intervening rain. Once $D_{0}$ is known, $N_{T}$ can be directly derived from the radar reflectivity at either wavelength if the snow density is either fixed or prescribed as a function of the snow particle size. As will be seen later, $\mathrm{N}_{\mathrm{T}}$ is not only sensitive to the snow density but also to the value of $\mu$.

We focus in the following sections on two separate case studies from CaPE that allow the comparisons of the results retrieved from the airborne dual-wavelength radar ( $\mathrm{X}$ and Ka bands) with in-situ airborne particle measurements as well as the snow size distribution parameters derived from $\mathrm{S}$ and $\mathrm{X}$ band ground-based radar.

\section{COMPARISON WITH IN-SITU MEASUREMENTS}

On 19 July 1991 (UT: 18:15-18:45) during the Convective and Precipitation Experiment (CaPE) conducted in the central Florida region during the period 8 July through 18 August 1991, a weak convective cell was observed by an airborne radar in coordination with in-situ measurements. These measurements offer an opportunity to check directly the airborne dual-wavelength algorithm for the estimates of snow parameters. The airborne radar, built by the Communication Research Laboratory of Japan, was installed on the NASA T-39 aircraft. Operating at X- and Ka-bands, the radar 
viewed the precipitation at nadir with beamwidths matched at 5 degrees. The in-situ particle measurements were made using a PMS 2D-P probe mounted on the T-28 aircraft of the South Dakota School of Mines \& Technology. Figure 5 illustrates the flight tracks of the T-39 and T-28 with an origin at longitude $-81.2^{\circ}$ and latitude $28.35^{\circ}$. The T-28 penetrated the storm twice where the start of track A occurred about 8 minutes before the start of the T-39 flight track leg and the start of track B about 3 minutes after the T-39 flight track. The offsets in space between the $\mathrm{T}-28$ and T-39, i.e., the horizontal distance between the T-28 aircraft and the nearest T-39 radar range gate, were generally within 5 $\mathrm{km}$ while the temporal offsets were within 8 minutes. For these flights the T-39 flew at an altitude of approximately $11 \mathrm{~km}$ while the T-28 flew at $5.2 \mathrm{~km}$. Figure 6 a displays the T39 measurements of the X-band radar reflectivities along the flight track direction shown in Fig.5. The origin in the plot coincides with the starting point of the T-39 flight track at time 18:36:03 UT. The white line shown in Fig. 6a indicates the T-28 flight altitude. The DFR derived from the $\mathrm{X}$ - and $\mathrm{Ka}$-band data at $5.2 \mathrm{~km}$ is plotted in Fig.6b.

Two regions can be clearly distinguished by viewing the magnitude of the DFR. Over the range from 3 to $7.5 \mathrm{~km}$ (region 1 ) the DFR attains levels as high as $6 \mathrm{~dB}$ whereas for distances exceeding $7.5 \mathrm{~km}$ (region 2) the average DFR is close to $1 \mathrm{~dB}$. Regions 1 and 2 correspond to the T-39 time segments of 18:36:03-18:36:38 UT and 18:36:38-18:37:14 UT, respectively, as shown in Fig.5. An examination of the T-28 PMS 2D-P images shows two main types of snow particles in this storm cell. For the period 18:28:4518:29:47 UT for track A and 18:40:49-18:42:10 UT for track B, the particles appear to be almost exclusively aggregates. The particles viewed during the period 18:29:47-18:32:04 UT for track A and 18:39:20-18:40:49 UT for track B are identified as graupel by their 
small, nearly spherical shape. Shown in Fig.7 are the examples of the T-28 PMS 2D-P images of the T-28 track A for the aggregates (top) measured from 18:29:15-18:29:19 UT and the graupel (bottom) from 18:30:50-18:30:54 UT. The snow aggregates typically have a low density $\left(0.05-0.2 \mathrm{~g} / \mathrm{cm}^{3}\right)$ while the mass densities of graupel lie between $0.4-$ $0.8 \mathrm{~g} / \mathrm{cm}^{3}$ (Battan, 1973). Since the attenuation is negligible in dry snow at these frequencies, then if the cloud liquid water can be neglected, the $\mathrm{D}_{0}$ can be directly obtained from the DFR by use of the DFR- $D_{0}$ relations shown in Figs. 1 and 2 . With use of $D_{0}$ and reflectivity at $X$ band, the number concentration $N_{T}$ can be computed. To compare with the in-situ measurements, the airborne radar retrieval was performed using data at the height of $5.2 \mathrm{~km}$ where the horizontal distance between the aircraft was smallest. To overcome offsets in space and time between the T-39 and T-28, a single shift of $3 \mathrm{~km}$ was made for the T-28 flight Track A and $2.5 \mathrm{~km}$ for the Track B to match the T-39 observations in the aggregate and graupel regions. In this way, comparisons of the $D_{0}$ and $N_{T}$ can be fairly made between the T-28 in-situ measurements and the T-39 airborne radar estimates. A detailed analysis of their comparisons will be given later.

To see how the snow particle size distributions are represented by the Gamma functions, we categorize the snow particles into the aggregates and graupel based on the in situ measurements of the T-28 flight tracks shown in Fig.5, and then parameterize the respective size distributions into the Gamma functions. Figure 8 is an example of the measurements of the size distributions of aggregates obtained from the T-28 PMS of Track A. The averaged distribution of the particle size is computed based on the measured data and plotted in the thick solid line. Using the same $D_{0}$ and $N_{T}$ of the measured mean distribution, the Gamma size distributions are plotted in Fig. 8 for $\mu$ of - 
0.5, 0 and 0.5. In general, the Gamma functions, as shown in Fig.8, reasonably describe the particle size spectra. Of these parameterization curves, however, the Gamma function with $\mu$ equal to -0.5 has the best fit for the measured data in view of their rms with respect to the measurements. Same conclusions are drawn from the analysis of the measured size spectra of aggregates from the Track B, i.e., the size distributions of aggregates are best represented by the Gamma functions if $\mu$ is taken to be -0.5 . For the case of graupel, it is found, from the results of parameterizations of the size spectra within the graupel regions of the T-28 Track A and B, that $\mu$ is set to 1 for the Gamma size distribution, yielding the smallest $\mathrm{rms}$ from the measured data. Therefore, the shape factor of the size distribution $\mu$, is chosen to be -0.5 for aggregates and 1 for graupel for our retrievals.

Illustrated in Fig.6c and 6d are the results of the comparisons between the T-28 measurements and the T-39 estimates. In the estimation of $D_{0}$ and $N_{T}$ from the T-39 radar, particle densities of $0.2 \mathrm{~g} / \mathrm{cm}^{3}$ and $0.7 \mathrm{~g} / \mathrm{cm}^{3}$ are taken to characterize, respectively, the aggregates and graupel in the two regions, which yield the best agreements. The 2D-P measures the maximum dimension of the particle, either along the $\mathrm{X}$ or $\mathrm{Y}$ axis, whichever length is larger, so that the median volume diameter, $\mathrm{D}_{0, \max }$, is expressed in terms of the maximum dimension. Therefore, to compare the estimates of particle size from the in-situ and radar measurements an account must be made for the differences between $\mathrm{D}_{0, \max }$ and $D_{0}$. For the graupel particles which are nearly spherical, the $D_{0, \max }$ and $D_{0}$ are approximately the same and therefore no adjustment is made. For the aggregates it is reasonable to assume that the $\mathrm{D}_{0, \max }$ is always larger than the $\mathrm{D}_{0}$ which, by definition, is the equivalent-volume diameter of the sphere. To account for this difference, we have 
scaled the $\mathrm{D}_{0}$ estimates from the dual-wavelength radar data by a factor of 1.5 . Although the adjustment of $D_{0}$ to $D_{0, \max }$ for aggregates depends on particle shape, orientation and size distribution, the scale factor of 1.5, used in Fig.6c, seems to work well for our comparisons. As indicated in Fig.6, the retrievals of $D_{0}$ and $N_{T}$ from the dual-wavelength radar measurements are fairly good. Some of the discrepancies between the retrieved and measured results may be attributable to offsets in the T-39 and T-28 flight tracks as well as the large differences between the sampling volumes of the radar and the PMS probe.

In Figs. 9 and 10, the inferred Gamma size distributions from the T-39 for aggregates and graupel expressed as the means of the results depicted in Fig. 6c and 6d, are compared with the T-28 measured mean size distributions. The procedures to obtain the averaged DSD spectra, $\overline{N(D)}$, over the aggregate and graupel regions are to sum all the derived (T-39) and measured (T-28) DSD in their respective regions and then divide by the number, $\mathrm{n}$, of corresponding DSD profiles. This operation can be expressed by the following equation:

$$
\overline{N\left(D_{j}\right)}=\frac{\sum_{i=1}^{n} N_{i}\left(D_{j}\right)}{n} ; \quad j=1, \ldots, m,
$$

where $D_{j}$ is the diameter of particle at the jth bin of size and $m$ the total number of size bins. The thick lines of Figs. 9 and 10 correspond to the T-28 measurements for the Track $\mathrm{A}$ and $\mathrm{B}$. For aggregates the scale factor of 1.5 , as mentioned earlier, is used for the radar-derived Gamma distributions. Despite somewhat variations of the measured spectra, demonstrated by the differences between the Track A and B, the inferred Gamma size distributions show an excellent agreement with the in-situ particle measurements for both aggregates and graupel. This is an encouraging result because the snow size 
distribution might be accurately derived from the $\mathrm{X}$ and $\mathrm{Ka}$ band radar if the shape factor of the Gamma distribution and the snow density are known.

To examine how the retrieval results vary as the different parameters are used, we repeat our computations for $D_{0}$ and $N_{T}$ with different values of $\rho$ and $\mu$. Let $\rho=\left(\rho_{1}, \rho_{2}\right)$ denote the snow density with $\rho_{1}$ and $\rho_{2}$ representing the aggregates and graupel, respectively. Figure 11 shows the comparisons of the computational results of $D_{0}$ and $N_{T}$ as the snow densities and $\mu$ are chosen at several values. Differences of the results between $\rho=(0.2,0.8)$ (solid lines) and $\rho=(0.1,0.6)$ (dashed lines) at $\mu=2$ in Fig. 11 exhibit the dependence of the estimated $D_{0}$ and $N_{T}$ on the snow density. As expected, the $D_{0}$ has little change with change of snow densities. In contrast, the $\mathrm{N}_{\mathrm{T}}$ changes dramatically. In view of the comparisons between $\mu=0$ (dotted-dashed lines) and $\mu=2$ for the snow densities $\rho=(0.2,0.8)$, a change of $\mu$ alters the results of both $D_{0}$ and $N_{T}$ but in different degrees. The consistency of the radar-derived size distributions has been checked by applying the dual-wavelength algorithm to the entire snow region of the T-39 radar measurements shown in Fig.6a. Illustrated in Fig. 12 are the results of the retrieved $D_{0}$ and $\mathrm{N}_{\mathrm{T}}$ for snow in the region above $5 \mathrm{~km}$. In the retrieval, the snow is classified as aggregates in the area where the DFR is greater than $3 \mathrm{~dB}$ and as graupel in the area where the DFR is less than $3 \mathrm{~dB}$ as determined from the data shown in Fig.6b. As in Figs.6c and 6d, the snow densities of aggregates and graupel are assumed to be 0.2 and $0.7 \mathrm{~g} / \mathrm{cm}^{3}$, respectively. Although the only in-situ data available were from the $\mathrm{T}-28$ flight lines at $5.2 \mathrm{~km}$, the results for $\mathrm{D}_{0}$ and $\mathrm{N}_{\mathrm{T}}$ in Figs. $6 \mathrm{~b}$ and $6 \mathrm{c}$ appear to be reasonably consistent with the in-situ data. 
We conclude that the median volume diameter of snow can be estimated reasonably well from dual-wavelength airborne radar operating at $\mathrm{X}$ and $\mathrm{Ka}$ bands. The $\mathrm{N}_{\mathrm{T}}$, on the other hand, is affected by the assumptions of the snow density and the shape factor of the Gamma distribution and can be accurately estimated only if the snow density and $\mu$ are known. The empirical relations that connect the snow density to the snow size, such as those given by Magano and Nakamura (1965) and Klaassen (1988), along with the information on $\mu$ based on a statistical analysis of in-situ particle measurements may improve the accuracy for the snow parameter retrievals.

\section{COMPARISON WITH GROUND-BASED RADAR}

During CaPE the T-39 was also coordinated with measurements from the groundbased NCAR CP-2 radar that operated at $\mathrm{S}$ and $\mathrm{X}$ bands. With the measurements of the CP-2 radar at two wavelengths the $D_{0}$, as shown in Figs. 3 and 4, can be estimated by the same procedure used for the $\mathrm{X}$ and $\mathrm{Ka}$ band data. As such, the consistency of the dualwavelength radar algorithm can be further examined by comparing estimated parameters of the particle size distributions from the collocated measurements between the ground and airborne radars. A challenge for this work is to precisely register the data sets, taken from two platforms, into the same coordinates. To map the data we first project the T-39 data onto the horizontal direction along which the RHI scan of the CP-2 radar was made. By applying a cross-correlation of the $\mathrm{T}-39$ and $\mathrm{CP}-2$ radar data, the registration of the data sets proceeds by shifting the T-39 radar measurements along the horizontal direction of the CP-2 until the cross-correlation is maximized. 
Shown in Fig. 13 are a set of observations of the T-39 and CP-2 radars taken on 16 July 1991 over a stratiform portion of a storm. The T-39 flight track (solid line) for the time period 21:33:50-21:40:43 UT is approximately collocated with the RHI scan (dashed line) of the CP-2 radar at 21:37:28 UT. Over a nearly $75 \mathrm{~km}$ flight leg over the rain, the spatial offsets between the T-39 and CP- 2 were smaller than $5 \mathrm{~km}$ for ranges, as measured from the $\mathrm{CP}-2$, of less than $40 \mathrm{~km}$. For ranges beyond $40 \mathrm{~km}$ the $\mathrm{T}-39$ was nearly perfectly aligned along the $\mathrm{CP}-2$ radial direction. The measured reflectivities of the airborne and ground-based radars are remapped in Fig.14 as a function of radial distance from the $\mathrm{CP}-2$ radar by means of the registration procedure described earlier. As shown in Fig.14, the two radars exhibit very similar storm structures except for a gap (missing data) in the T-39 radar data. With its fairly high vertical resolution $(30 \mathrm{~m})$ the bright band is well defined by the T-39 airborne radar. For the case of the CP-2 radar, where the vertical resolution degrades gradually as the horizontal range increases, the bright band is clearly detected only for distances less than about $40 \mathrm{~km}$. Unlike the T-39 $\mathrm{X}$ and $\mathrm{Ka}$ band radar, the DFR for $\mathrm{S}$ and $\mathrm{X}$ bands are relatively small and the estimates appear noisy. Thus, an estimate of $D_{0}$ from the $S$ and $X$ bands requires averaging a sufficiently large number of measurements in time and space so that the DFR can be effectively extracted. For this reason, the comparisons of the snow parameters between the CP-2 and T-39 radars are restricted to the mean vertical and horizontal profiles of DFR.

To compare the T-39 and CP-2 radar estimates, the data are used only if the reflectivity factors measured from each radar exceeds its respective minimum detectable signal. Plotted in Fig.15 are the vertical (top) and horizontal (bottom) profiles of the $\mathrm{D}_{0}$ 
estimated from the mean profiles of DFR in the snow region (above radar bright band). Because of appearance of the radar bright band as shown in Fig.14, the measurements are associated with stratiform storm in which the aggregates typically dominate. The snow density is therefore taken to be $0.2 \mathrm{~g} / \mathrm{cm}^{3}$ and $\mu$ to be -0.5 for the radar retrieval of $D_{0}$, which is consistent with the values used in Fig. 6 for the case of aggregates. Although the $\mathrm{D}_{0}$ from the CP-2 data, as expected, exhibits large fluctuations, it nevertheless shows clear trends in both vertical and horizontal directions. In general, these trends are consistent with the more stable results from the T-39 radar data. Overall, the estimates of $\mathrm{D}_{0}$ of the T-39 and CP-2 radar data are correlated fairly well for both the vertical and horizontal profiles. It is worth mentioning that the profiles of $\mathrm{D}_{0}$ from the $\mathrm{CP}-2$ radar are sensitive to the assumed values of snow density and $\mu$ used in the retrieval while those from the T-39 radar remain relatively stable, independent of the snow density and $\mu$. This difference can be understood by comparing the results of Figs. 1 and 2 with those of Figs. 3 and 4; in particular, the fractional error in $D_{0}$ with changes in $\rho$ and $\mu$ is much smaller for the 10 and $35 \mathrm{GHz}$ combination than it is for the 3 and $10 \mathrm{GHz}$ set. Note that the reflectivities of the $S$ and $X$ bands of the CP-2 radar, used for the estimates of the snow parameters, have been corrected to take into account the rain attenuation by using standard $\mathrm{k}-\mathrm{Z}$ relations (Battan, 1973), where $\mathrm{k}$ is the specific attenuation coefficient (dB/km). The results of $\mathrm{N}_{\mathrm{T}}$ from the CP-2 radar (not shown) fluctuate strongly because of the dependence on the snow density and $\mu$. As a result of this uncertainty, the comparisons of $\mathrm{N}_{\mathrm{T}}$ are not instructive.

\section{SUMMARY}


A description was presented of a dual wavelength radar algorithm to estimate characteristics of the snow size distribution. For the cases of the airborne T-39 and ground-based CP-2 radars, the computations of the DFR, with respect to the several snow densities and $\mu$, were made as a function of $D_{0}$. Analysis of the results indicates that the DFR- $\mathrm{D}_{0}$ relations for the pair of the $\mathrm{X}$ and $\mathrm{Ka}$ band wavelengths of the T-39 radar are nearly independent of the snow density for most values of $D_{0}$, and have only modest sensitivity to the $\mu$ parameter of the Gamma size distribution. The fact that the DFR depends primarily on $\mathrm{D}_{0}$ suggests that accurate estimates of the particle size distributions should be possible if the particles are sufficiently large relative to the shorter wavelength and if the attenuation can be either neglected or corrected. Once $D_{0}$ is estimated, the $N_{T}$ can be directly derived from either of the reflectivities at two wavelengths. The $\mathrm{N}_{T}$, however, depends on the snow density and the assumed $\mu$. This may lead to an error if an inaccurate snow density or $\mu$ are used. The results also indicate that the combination of $\mathrm{X}$ and $\mathrm{Ka}$ bands is far superior in terms of stability and accuracy to the $\mathrm{S}$ and $\mathrm{X}$ band combination for inferring snow characteristics as long as attenuation from cloud water can either be neglected or corrected for.

Validation of the dual-wavelength techniques was performed by comparing the derived snow parameters and size distributions from the T-39 airborne radar with direct particle measurements. Having carefully registered the particle information obtained from the aircraft in-situ PMS measurements, the radar-derived characteristic snow parameters and of size distributions were compared with the measurements. We find that the radar results agree reasonably well with those from the direct measurements by the PMS. Moreover, based on an examination of the PMS 2D images, the signatures of the DFR of 
the T-39 radar are quite sensitive to the type of the snow particle. From the measurements of the T-39 radar used in our study, the DFR of aggregates appears to be several times greater than that for the graupel. This feature of the DFR, if true for general cases, should help to identify snow type by means of the dual-wavelength radar. Confirmation of this feature requires further study as well as more coordinated radar and particle in-situ measurements. It is also found, from the comparisons, that use of the snow densities of $0.2 \mathrm{~g} / \mathrm{cm}^{3}$ for aggregates and $0.7 \mathrm{~g} / \mathrm{cm}^{3}$ for graupel for the radar retrieval gives the best agreement. The shape factors of the Gamma size distributions are -0.5 for aggregates and 1 for graupel based on the parametric fits of the in situ particle measurements.

To check the consistency of the retrieval, comparisons of $D_{0}$ estimates were also made using the T-39 airborne and ground-based CP-2 radars for a stratiform storm from one set of coordinated measurements. Due to the strong fluctuations of the DFR from the CP-2 radar, the comparisons are made only on the mean profiles of the horizontal and vertical measurements of snow above the radar bright band. With the use of the snow density of $0.2 \mathrm{~g} / \mathrm{cm}^{3}$ and $\mu$ of -0.5 , it is shown that the retrievals of $D_{0}$ from both radars are consistent despite the fluctuations of the results from the $\mathrm{CP}-2$. We conclude that the use of dual-wavelength radar, with properly chosen wavelengths, should provide useful estimates of the microphysical properties of hydrometeors. The GPM Precipitation Radar, operating at frequencies of $\mathrm{Ku}$ band $(13.8 \mathrm{GHz})$ and $\mathrm{Ka}$ band, has a great deal of similarity to the X and Ka-band combination used on the aboard T-39 aircraft in terms of the general behavior of the DFR- $\mathrm{D}_{0}$ relationship. As a consequence, our findings in this study have direct applications to estimation of snow in mid- and high-latitude regions. It 
is anticipated that the GPM radar will play an important role in mapping the microphysical properties of hydrometeors globally.

\section{ACKNOWLEDGEMENTS}

We wish to thank NCAR for providing the CP-2 radar data and its processing software. The T-28 operations were supported by the NSF Lower Atmospheric Observing Facilities program. We wish to thank Peter Bradfield and GSFC/Wallops Flight Facility for support of the T-39 operations. 


\section{REFERENCES}

Battan, L. J., 1973: Radar Observation of the Atmosphere. University of Chicago, 324 pp.

Boucher, R. J., and J. G. Wieler, 1985: Radar determination of snowfall rate and accumulation. J. Climate Appl. Meteor., 24, 68-73.

Braham, R. R., Jr., 1990: Snow particle size spectra in lake effect snows. J. Appl. Meteor., 29, 200-207.

Bringi, V., G. Huang, V. Chandrasekar and E. Gorgucci, 2002: A methodology for estimating the parameters of a Gamma raindrop size distribution model from polarimetric radar data: Application to a squall-line event from the TRMM/Brazil campaign. J. Oceanic and Atmos. Tech., 19, 633-645.

Bruggeman, D. A. G., 1935: Berechnung verschiedener Konstanten von heterogenen Substanzen: I. Dielectrizitatskonstanten und Leifahigkeiten der Mischkorper aus isotropen Substanzen. Ann. Phys., 24, 636-679.

Carlson, R. E., and J. S. Marshall, 1972: Measurement of snowfall by radar. J. Appl. Meteor., 11, 494-500.

Debye, P., 1929: Polar Molecules. Dover, 172 pp.

Gorgucci, E., G. Scarchilli, V. Chandrasekar and V. Bringi, 2001: Estimation of raindrop size distribution parameters from polarimetric radar measurements. J. Atmos. Sci., 59, 2373-2384.

Gorgucci, E., G. Scarchilli, V. Chandrasekar and V. Bringi, 2002: Measurement of mean raindrop shape from polarimetric radar observations. J. Atmos. Sci., 57, 3406-3413.

Gunn, K. L. S., and J. S. Marshall, 1958: The distribution with size of aggregate snowflakes. J. Meteor.,15, 452-461. 
Iguchi, T., R. Oki, E.A. Smith and Y. Furuhama, 2002: Global Precipitation Measurement program and the development of dual-frequency precipitation radar. $J$. Commun. Res. Lab. (Japan), 49, 37-45.

Imai, I., M. Fujiwara, I. Chimura and Y. Toyama, 1955: Radar reflectivity of falling snow. Papers Meteor. Geophys. (Japan), 6, 130-139.

Klaassen, W.., 1988: Radar observations and simulation of the melting layer of precipitation. J. Atmos. Sci., 45, 3741-3753.

Liao, L., R. Meneghini, T. Iguchi and A. Detwiler, 1997: Estimation of snow parameters from dual-wavelength airborne radar. Preprints $28^{\text {th }}$ Conf. Radar Meteor., American Meteor. Soc., 510-511.

,$------\cdots--, 2000$ : Investigation of the dielectric constants of inhomogeneous air-ice and snow-water spheres. Proc. IEEE 2000 Int. Geoscience and Remote Sensing Symp., Honolulu, HI, IEEE, 1804-1806.

Locatelli, J. D., and P. V. Hobbs, 1974: Fall speeds and masses of solid precipiatation particles. J. Geophys. Res., 79, 2185-2197.

Loffler-Mang, M., and U. Blahak, 2001: Estimation of the equivalent radar reflectivity factor from measured snow size spectra. J. Appl. Meteor., 40, 843-849.

Magono, C., 1957: On snowflakes. Proc. Sixth Weather Radar Conf., Boston, Amer. Meteor. Soc., 31-36.

-----, and T. Nakamura, 1965: Aerodynamic studies of falling snow flakes. J. Met. Soc., Japan, 43, 139-147. 
Mardiana, R., T. Iguchi, and N. Takahashi, 2004: A dual-frequency rain profiling method without the use of surface reference technique. IEEE Trans. Geosci. Remote Sens., 42, 2214-2225.

Matrosov, S. Y., 1992: Radar reflectivity in snowfall. IEEE Trans. Geosci. Remote Sens., 30, 454-461.

-----, 1998: A dual-wavelength radar method to measure snowfall rate. J. Appl. Meteor., 7, 1510-1521.

Maxwell-Garnett, J. C., 1904: Colors in metal glasses and in metallic films. Philos. Trans. Roy. Soc. London, 203A, 385-420.

Meneghini, R., T. Kozu, H. Kumagai, and W. C. Boncyk, 1992: A study of rain estimation methods from space using dual-wavelength radar measurements at nearnadir incidence over ocean. J. Atmos. Oceanic Technol., 9, 364-382.

-----, and H. Kumagai, 1994: Characteristics of the vertical profiles of dual-frequency, dual-polarization radar data in stratiform rain. J. Atmos. Oceanic Technol., 11, 701711.

------, H. Kumagai, J. Wang, T. Iguchi and T. Kozu, 1997: Microphysical retrievals over stratiform rain using measurements from an airborne dual-wavelength radarradiometer. IEEE Trans. Geosci. Remote Sens., 29, 690-703.

-----, and L. Liao, 1996: Comparisons of cross sections for melting hydrometeors as derived from dielectric mixing formulas and a numerical method. J. Appl. Meteor., $35,1658-1670$.

-.---, ----, 2000: Effective dielectric constants of mixed-phased hydrometeors. $J$. Atmos. Oceanic Technol., 17, 628-640. 
----, -----, S. Bidwell and G. M. Heymsfield, 2001: On the feasibility of a Doppler weather radar for estimates of drop size distribution using two closely spaced frequencies. IEEE Trans. Geosci. Remote Sens., 39, 2203-2216.

Ohtake, T., 1968: Change of size distribution of hydrometeors through a melting layer. Proc. Thirteen Radar Meteor. Conf., Boston, Amer. Meteor. Soc., 148-153.

Sekhon, R. S., and R. C. Srivastava, 1970: Snow size spectra and radar reflectivity. $J$. Atmos. Sci., 27, 299-307.

Simpson, J., C. Kummerow, W.-K. Tao, and R. F. Adler, 1996: On the Tropical Rainfall Measuring Mission (TRMM). Meteor. Atmos. Phys., 60, 19-36.

Smith, P. L., 1984: Equivalent radar reflectivity factors for snow and ice particles. $J$. Climate Appl. Meteor., 23, 1258-1260.

Vivekanandan, J, G. Zhang, and M. K. Politovich, 2001: An assessment of droplet size and liquid water content derived from dual-wavelength radar measurements to the application of aircraft icing detection. J. Atmos. Oceanic Technol., 18, 1787-1798. 
Figure Captions:

Fig.1 DFR versus $D_{0}$ for the snow densities of $0.8,0.6,0.4,0.2$ and $0.05 \mathrm{~g} / \mathrm{cm}^{3}$ when $\mu=2$ for the $\mathrm{T}-39$ airborne radar ( $\mathrm{X}$ and Ka bands).

Fig.2 DFR versus $D_{0}$ for $\mu$ of $-0.5,0,2,4$ and 6 when the snow density is $0.2 \mathrm{~g} / \mathrm{cm}^{3}$ for the T-39 airborne radar ( $\mathrm{X}$ and $\mathrm{Ka}$ bands).

Fig.3 DFR versus $D_{0}$ for the snow densities of $0.8,0.6,0.4,0.2$ and $0.05 \mathrm{~g} / \mathrm{cm}^{3}$ when $\mu=2$ for the CP-2 ground-based radar ( $\mathrm{S}$ and $\mathrm{X}$ bands).

Fig.4 DFR versus $D_{0}$ for $\mu$ of $0,2,4,6$ and 8 when the snow density is $0.2 \mathrm{~g} / \mathrm{cm}^{3}$ for the CP-2 ground-based radar ( $S$ and $\mathrm{X}$ bands).

Fig.5 Flight tracks of the T-39 and T-28 aircraft during observations of a weak convective cell with an origin at longitude $-81.2^{\circ}$ and latitude $28.35^{\circ}$. Time stamps are given at selected positions.

Fig.6 Airborne radar measurements over a weak convective cell and retrievals of the size distributions in comparisons with the in-situ particle measurements: (a) T-39 radar measured reflectivity at nadir along the flight track shown in Fig.5, (b) DFR of X and Ka bands at the altitude where the T-28 flew, as indicated by the white line in Fig.6a, (c) comparisons of $D_{0}$ between the radar estimated and the 2D-P measured results and (d) 
similar comparison for $\mathrm{N}_{\mathrm{T}}$. Note that the values of $\rho$ and $\mu$ for the radar retrieval are 0.2 $\mathrm{g} / \mathrm{cm}^{3}$ and -0.5 for aggregates and $0.7 \mathrm{~g} / \mathrm{cm}^{3}$ and 1 for graupel, respectively.

Fig.7 PMS 2D-P images taken from the T-28 aircraft of the South Dakota School of Mines \& Technology. The images taken around 18:29:15 UT for 4 seconds (top) are exclusively consisted of aggregates while the measurements taken around 18:30:50 UT (bottom) are made of graupel.

Fig.8 Measurements of the T-28 in-situ particle size distributions of snow aggregates from Track A. The thick solid line represents the averaged size distribution of the measured data. The Gamma size distributions are also plotted for the parameter $\mu$ of $0.5,0$, and 0.5 . The $\mathrm{D}_{0}$ and $\mathrm{N}_{\mathrm{T}}$ are respectively set to $3.5 \mathrm{~mm}$ and $3231 \mathrm{~m}^{-3}$, the mean values of the median volume diameter and particle number concentration from the measurements.

Fig.9 Comparisons of the snow size distributions of aggregates from the T-28 in-situ measurements and the T-39 radar retrievals. The average values of $\mathrm{D}_{0}$ and $\mathrm{N}_{\mathrm{T}}$ are respectively $3.5 \mathrm{~mm}$ and $3231 \mathrm{~m}^{-3}$ for the T-28 Track A, $4.2 \mathrm{~mm}$ and $1754 \mathrm{~m}^{-3}$ for the T28 Track B, and $2.6 \mathrm{~mm}$ and $2314 \mathrm{~m}^{-3}$ for the T-39 radar estimates. For the T-28 data, $\mathrm{D}_{0}$ denotes the median maximum dimension of particles; the radar-derived median volume diameter, $\mathrm{D}_{0}$, has been scaled by a factor of 1.5 for comparison purposes. 
Fig.10 Comparisons of the snow size distributions of graupel from the T-28 in-situ measurements and the T-39 radar retrievals. The values of $D_{0}$ and $N_{T}$ are respectively 1.4 $\mathrm{mm}$ and $4488 \mathrm{~m}^{-3}$ for the T-28 Track A, $1.02 \mathrm{~mm}$ and $2125 \mathrm{~m}^{-3}$ for the T-28 Track B, and $1.02 \mathrm{~mm}$ and $3433 \mathrm{~m}^{-3}$ for the T-39 radar estimates.

Fig.11 Comparisons of $\mathrm{D}_{0}$ (top) and $\mathrm{N}_{\mathrm{T}}$ (bottom) retrieved from the data of the T-39 radar shown in Fig.6a and $6 b$ at the different $\mu$ and the combinations of the snow densities. For example, the combination of the snow densities, $\rho=(0.1,0.6)$, stands for the snow densities of $0.1 \mathrm{~g} / \mathrm{cm}^{3}$ for aggregates and $0.6 \mathrm{~g} / \mathrm{cm}^{3}$ for graupel, respectively.

Fig.12 Maps of $\mathrm{D}_{0}$ and $\mathrm{N}_{\mathrm{T}}$ derived from the $\mathrm{T}-39$ radar measurements, as shown in Fig.6a, within the snow region where the altitude of radar echoes is greater than $5 \mathrm{~km}$ above the surface: (a) measured DFR of $X$ and Ka bands, (b) $D_{0}$ in $m m$ and (c) $\mathrm{N}_{\mathrm{T}}$ in $\mathrm{m}^{-3}$.

Fig.13 Map of the T-39 flight track (solid line) in reference to the NCAR CP-2 radar. The dashed line represents direction along which the RHI scan of the CP-2 was taken. Distances in $\mathrm{km}$ from the CP-2 are shown along the dashed line.

Fig.14 Radar measured reflectivity factors of the T-39 airborne radar (top two images) and the CP-2 ground radar (bottom two images) in terms of the distance from the CP-2. The data are the measurements corresponding to the T-39 flight track and the CP-2 RHI scan, shown as the solid and dashed lines in Fig. 13, respectively. 
Fig.15 Comparisons of the vertical (top) and horizontal (bottom) profiles of $D_{0}$ as derived from the T-39 airborne and CP-2 ground-based radars in the snow region. 


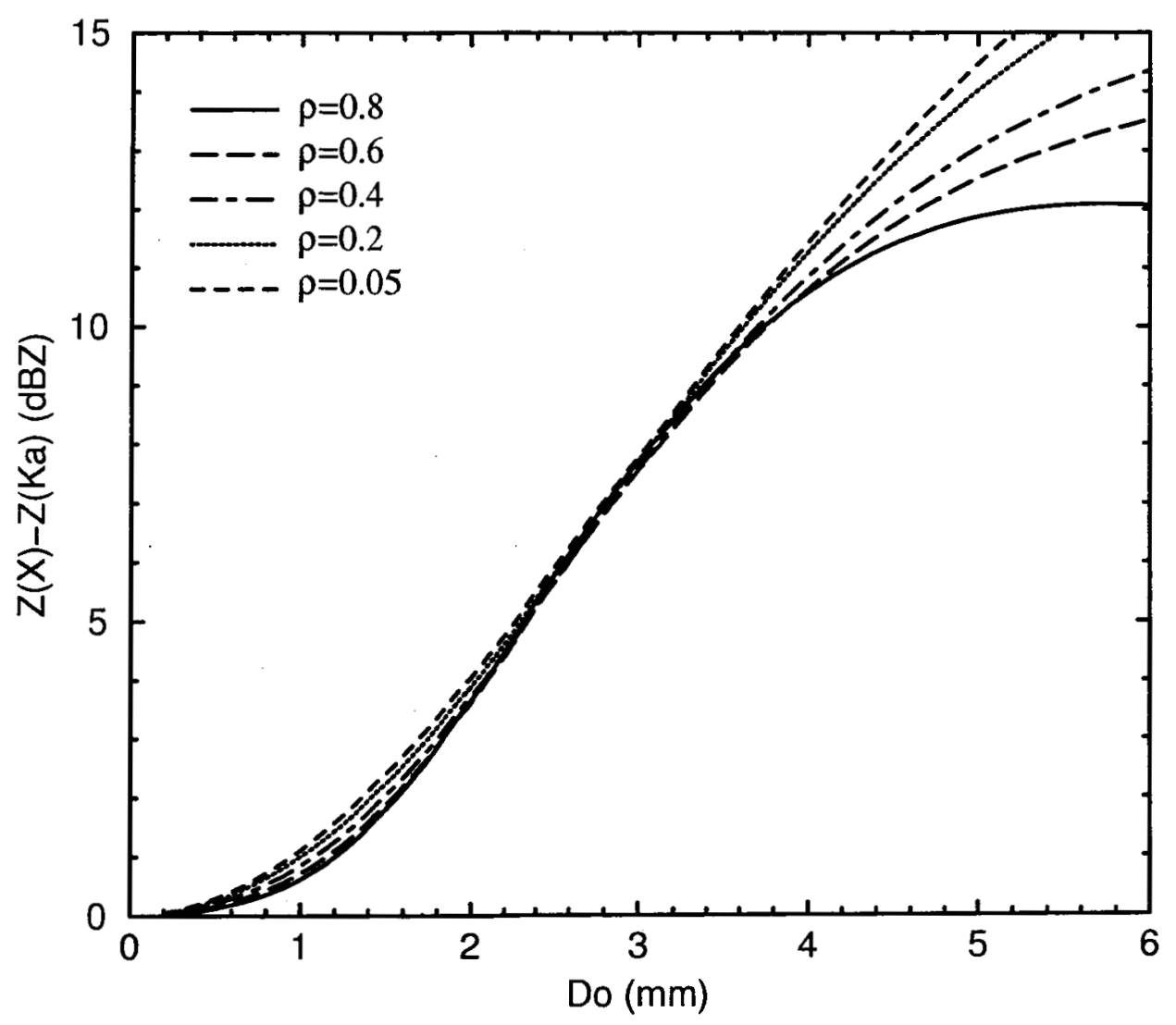

Fig.1 DFR versus $D_{0}$ for the snow densities of $0.8,0.6,0.4,0.2$ and $0.05 \mathrm{~g} / \mathrm{cm}^{3}$ when $\mu=2$ for the T-39 airborne radar ( $\mathrm{X}$ and $\mathrm{Ka}$ bands). 


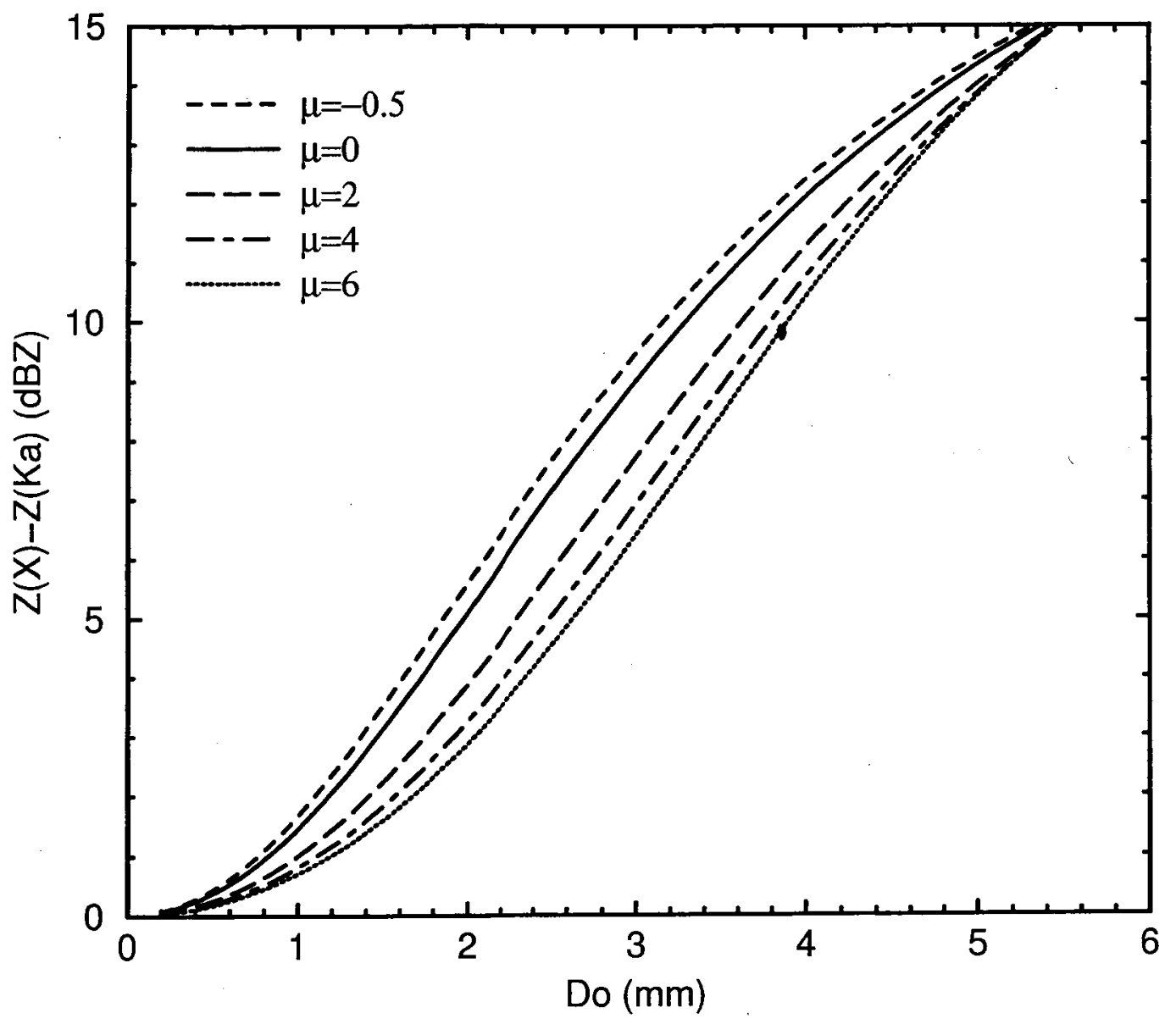

Fig.2 DFR versus $D_{0}$ for $\mu$ of $-0.5,0,2,4$ and 6 when the snow density is $0.2 \mathrm{~g} / \mathrm{cm}^{3}$ for the T-39 airborne radar ( $\mathrm{X}$ and $\mathrm{Ka}$ bands). 


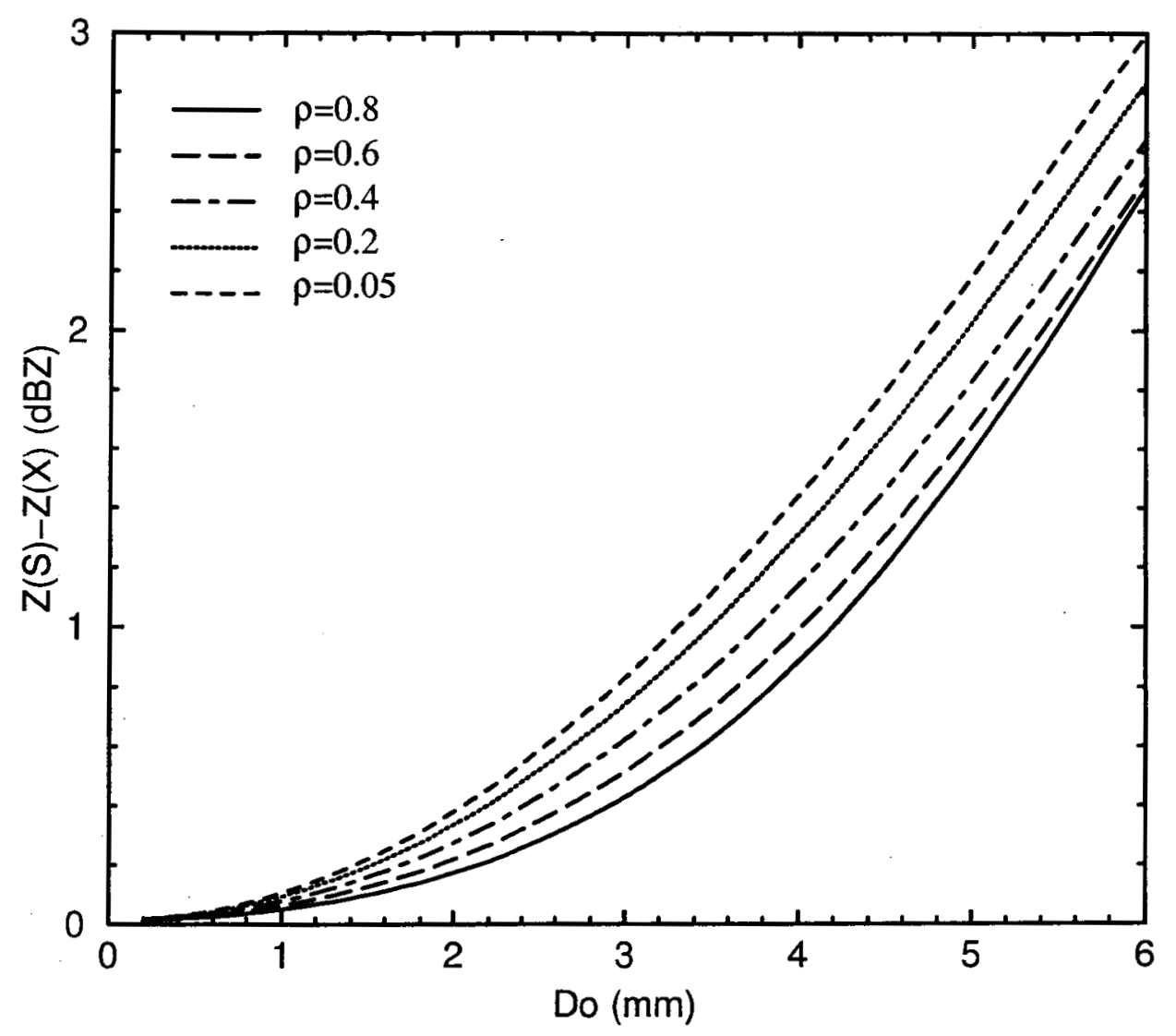

Fig.3 DFR versus $D_{0}$ for the snow densities of $0.8,0.6,0.4,0.2$ and $0.05 \mathrm{~g} / \mathrm{cm}^{3}$ when $\mu=2$ for the CP-2 ground-based radar ( $\mathrm{S}$ and $\mathrm{X}$ bands). 


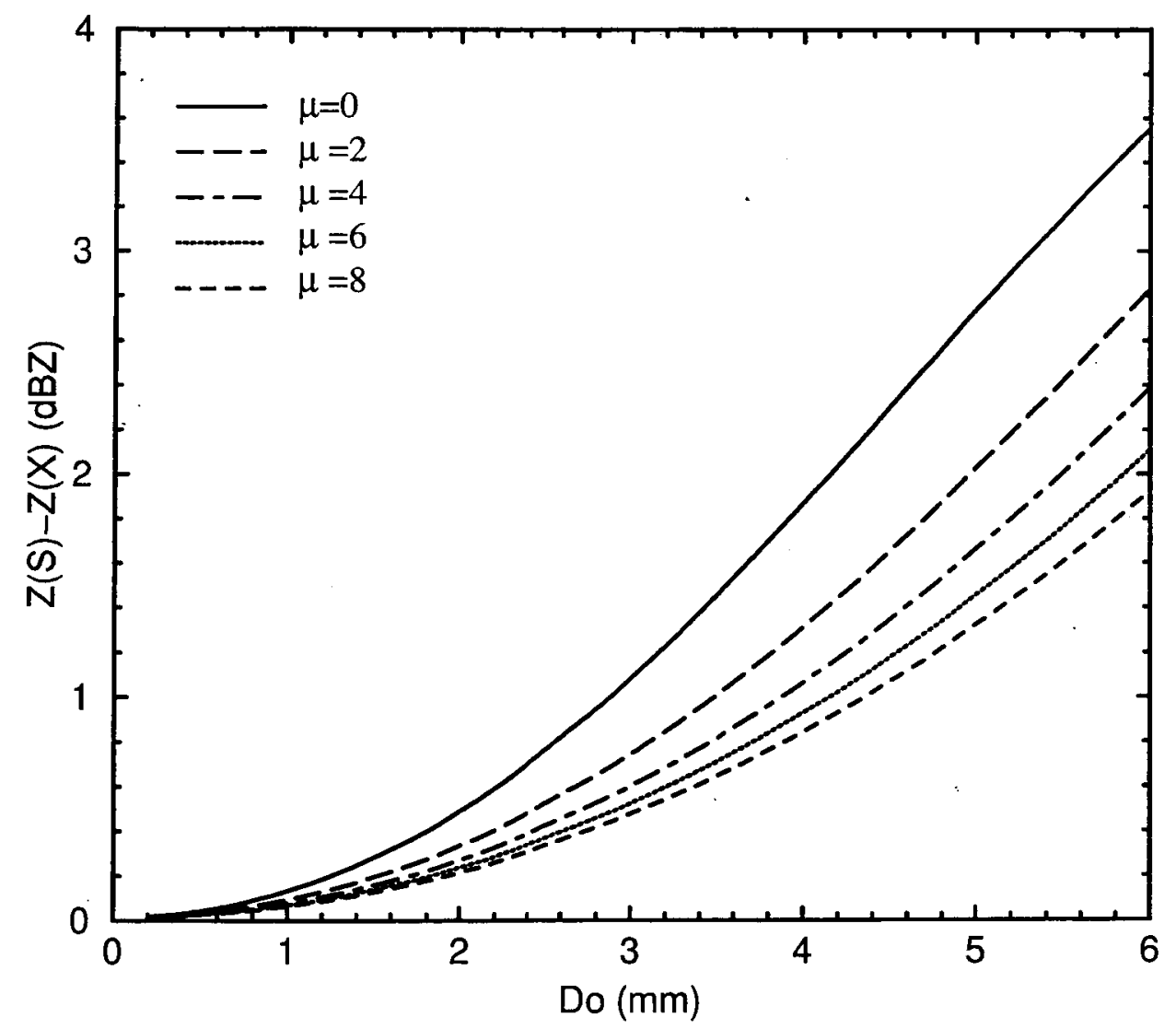

Fig.4 DFR versus $D_{0}$ for $\mu$ of $0,2,4,6$ and 8 when the snow density is $0.2 \mathrm{~g} / \mathrm{cm}^{3}$ for the CP-2 ground-based radar ( $\mathrm{S}$ and $\mathrm{X}$ bands). 


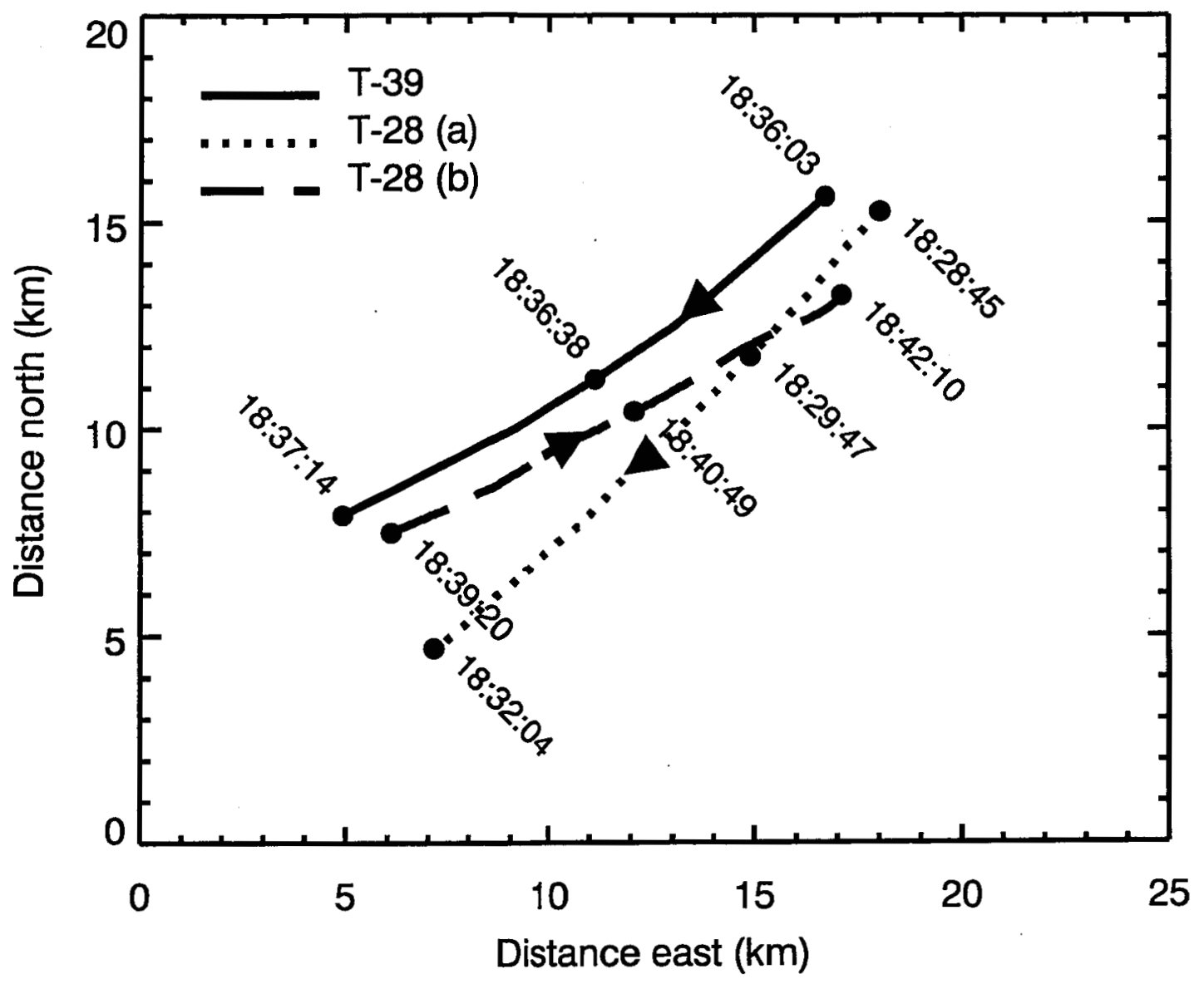

Fig.5 Flight tracks of the T-39 and T-28 aircraft during observations of a weak convective cell with an origin at longitude $-81.2^{\circ}$ and latitude $28.35^{\circ}$. Time stamps are given at selected positions. 

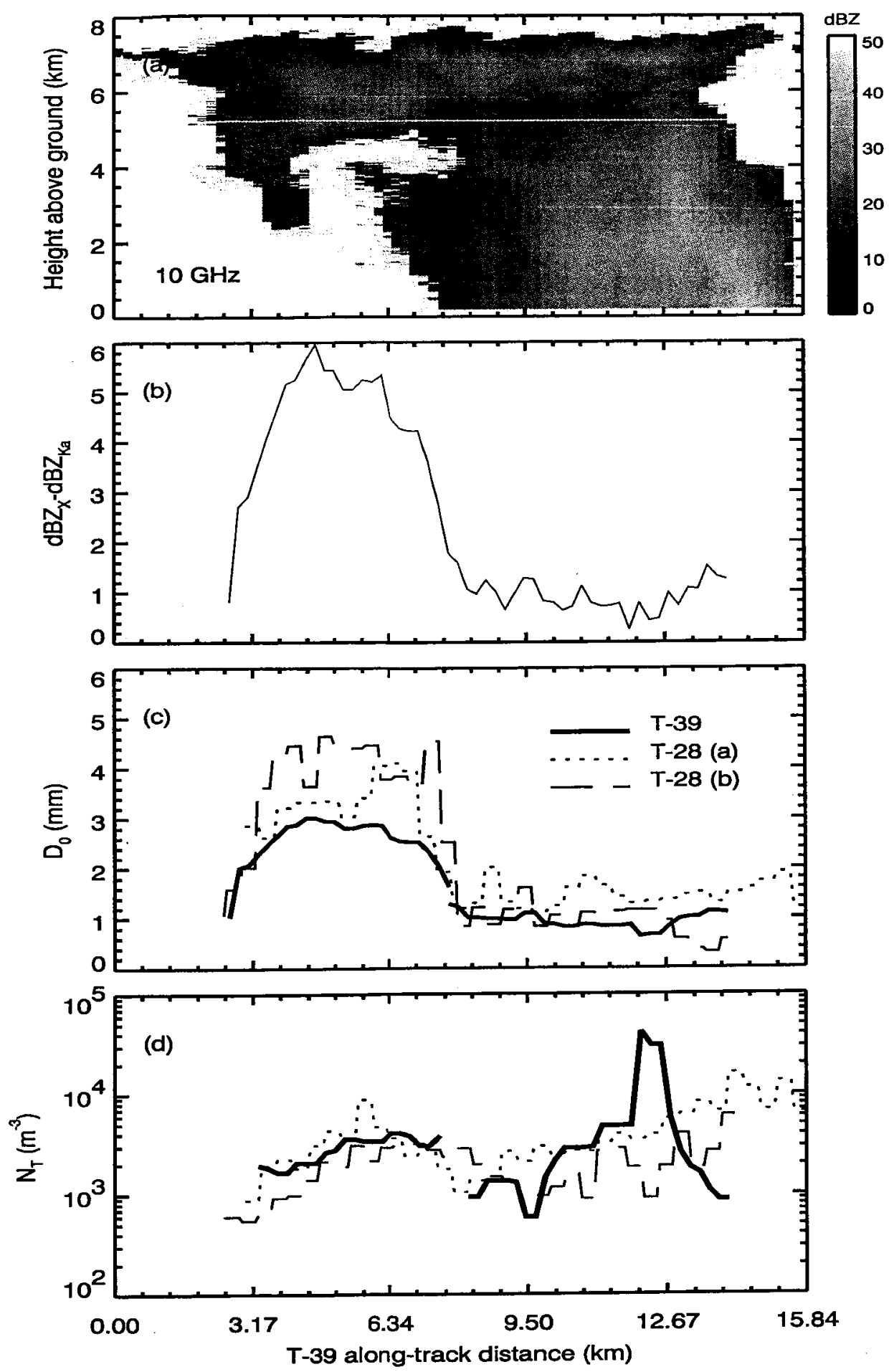

Fig.6 Airborne radar measurements over a weak convective cell and retrievals of the size distributions in comparisons with the in-situ particle measurements: (a) T-39 radar measured reflectivity at nadir along the flight track shown in Fig.5, (b) DFR of X and Ka bands at the altitude where the T-28 flew, as indicated by the white line in Fig.6a, (c) comparisons of $D_{0}$ between the radar estimated and the 2D-P measured results and (d) similar comparison for $\mathrm{N}_{\mathrm{T}}$. Note that the values of $\rho$ and $\mu$ for the radar retrieval are $0.2 \mathrm{~g} / \mathrm{cm}^{3}$ and -0.5 for aggregates and $0.7 \mathrm{~g} / \mathrm{cm}^{3}$ and 1 for graupel, respectively. 

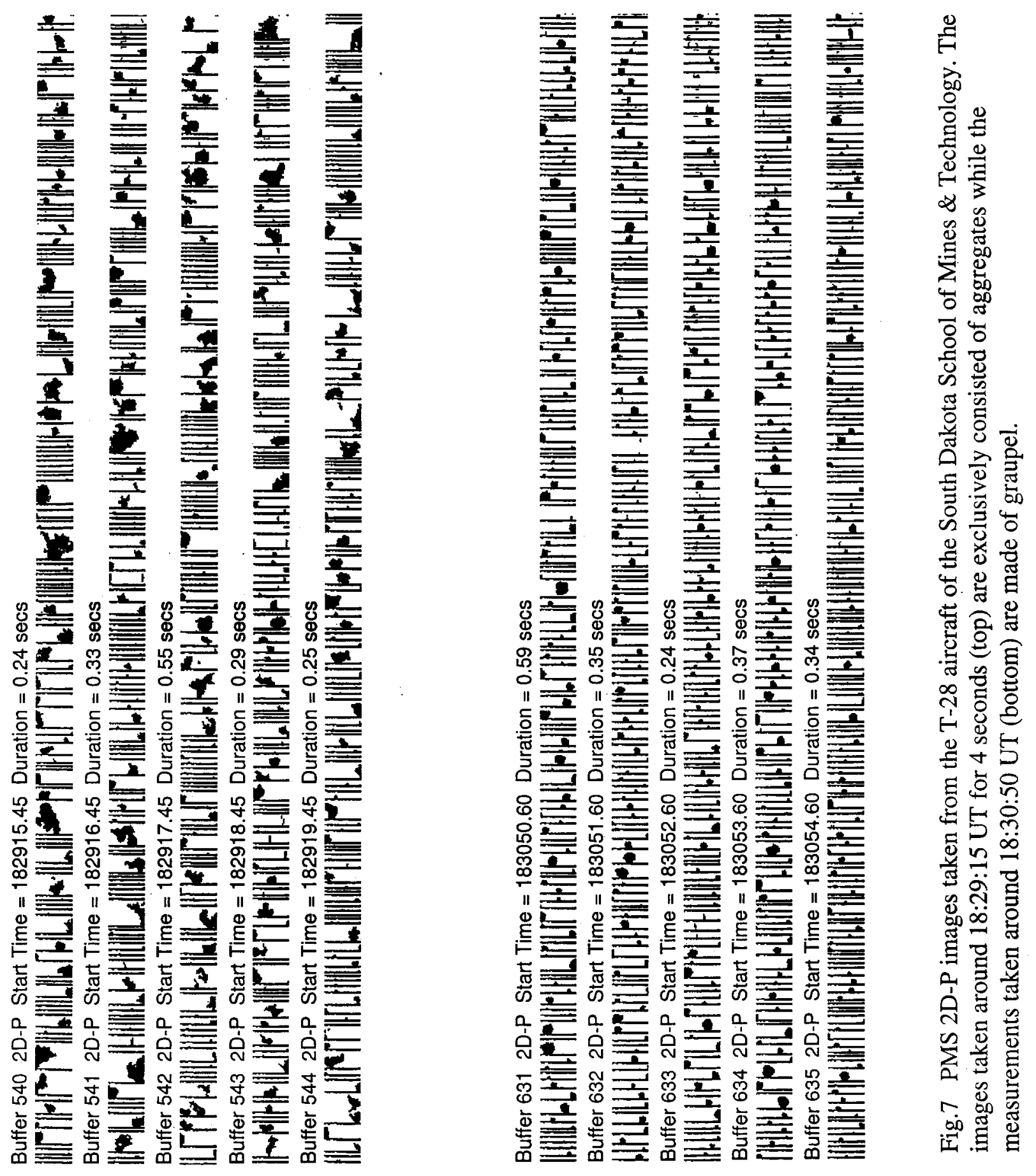


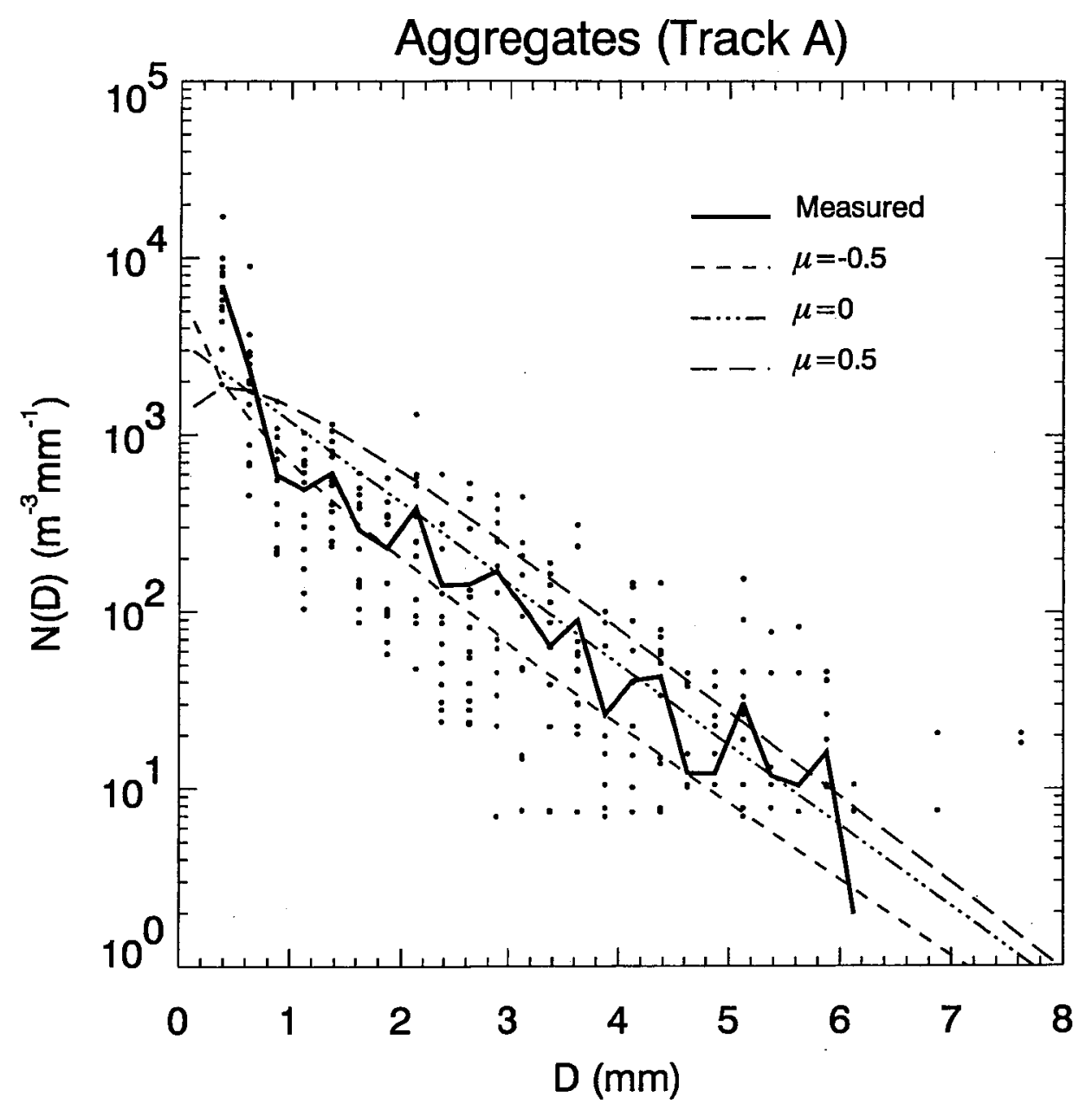

Fig.8 Measurements of the T-28 in-situ particle size distributions of snow aggregates from Track A. The thick solid line represents the averaged size distribution of the measured data. The Gamma size distributions are also plotted for the parameter $\mu$ of $-0.5,0$, and $0.5 . \mathrm{D}_{0}$ and $\mathrm{N}_{\mathrm{T}}$ are respectively set to $3.5 \mathrm{~mm}$ and $3231 \mathrm{~m}^{-3}$, the mean values of the median volume diameter and particle number concentration from the measurements. 


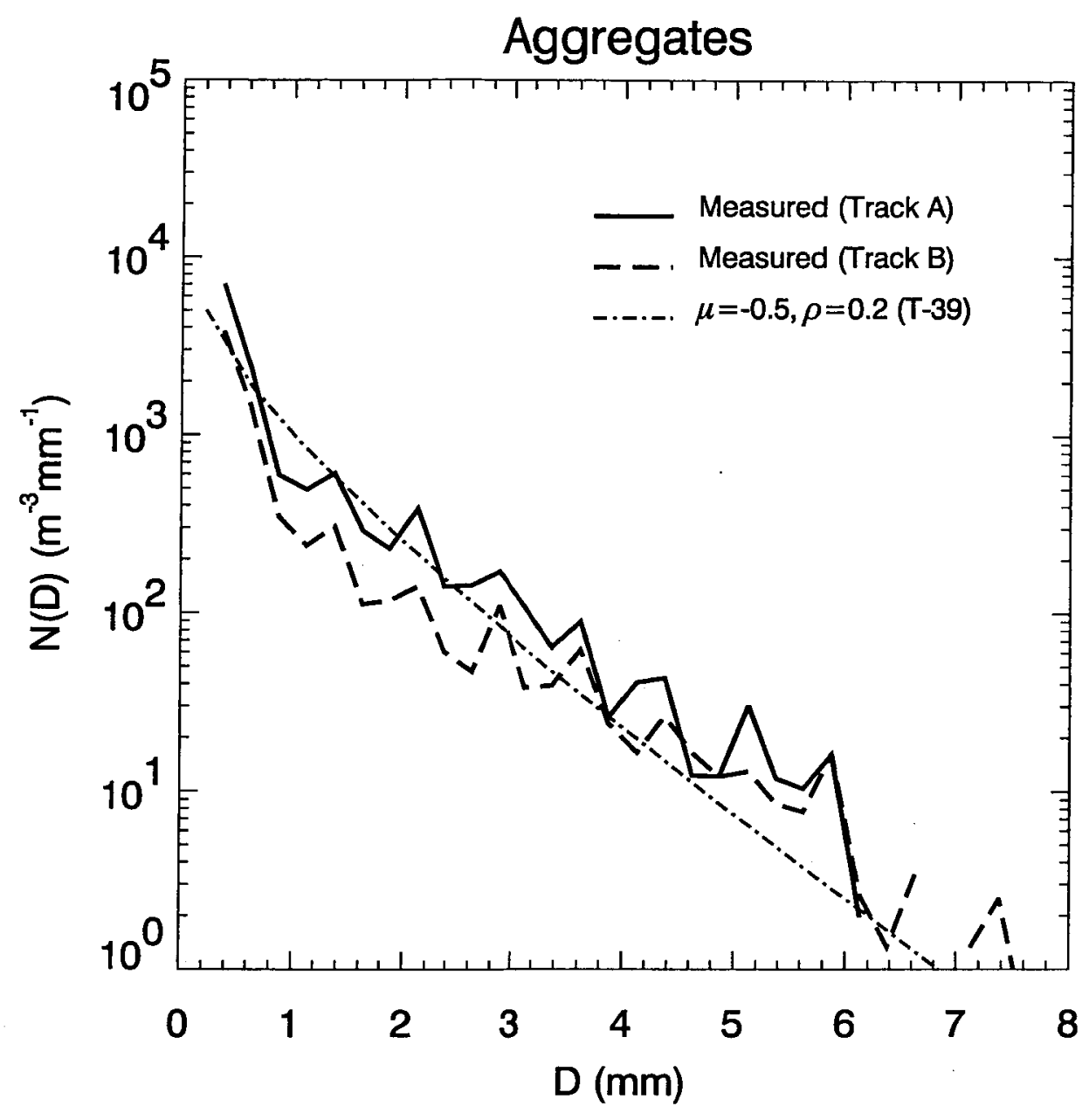

Fig.9 Comparisons of the snow size distributions of aggregates from the T-28 in-situ measurements and the T-39 radar retrievals. The average values of $\mathrm{D}_{0}$ and $\mathrm{N}_{T}$ are respectively $3.5 \mathrm{~mm}$ and $3231 \mathrm{~m}^{-3}$ for the T-28 Track $\mathrm{A}, 4.2 \mathrm{~mm}$ and $1754 \mathrm{~m}^{-3}$ for the $\mathrm{T}-28$ Track B, and $2.6 \mathrm{~mm}$ and $2314 \mathrm{~m}^{-3}$ for the $\mathrm{T}-39$ radar estimates. For the T-28 data, $\mathrm{D}_{0}$ denotes the median maximum dimension of particles; the radar-derived median volume diameter, $D_{0}$, has been scaled by a factor of 1.5 for comparison purposes. 


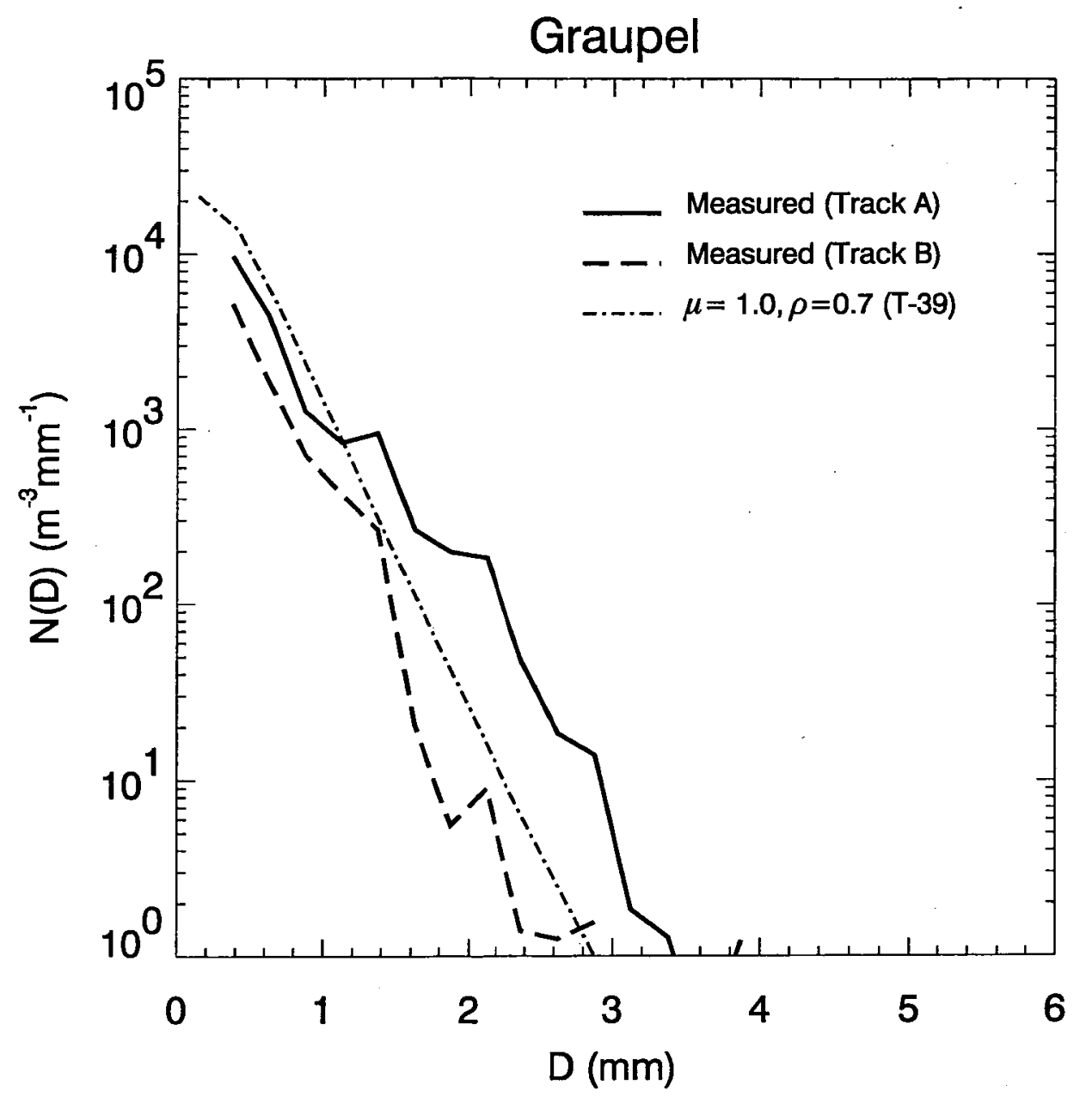

Fig.10 Comparisons of the snow size distributions of graupel from the T-28 in-situ measurements and the T-39 radar retrievals. The values of $D_{0}$ and $N_{T}$ are respectively 1.4 $\mathrm{mm}$ and $4488 \mathrm{~m}^{-3}$ for the T-28 Track A, $1.02 \mathrm{~mm}$ and $2125 \mathrm{~m}^{-3}$ for the T-28 Track B, and $1.02 \mathrm{~mm}$ and $3433 \mathrm{~m}^{-3}$ for the T-39 radar estimates. 


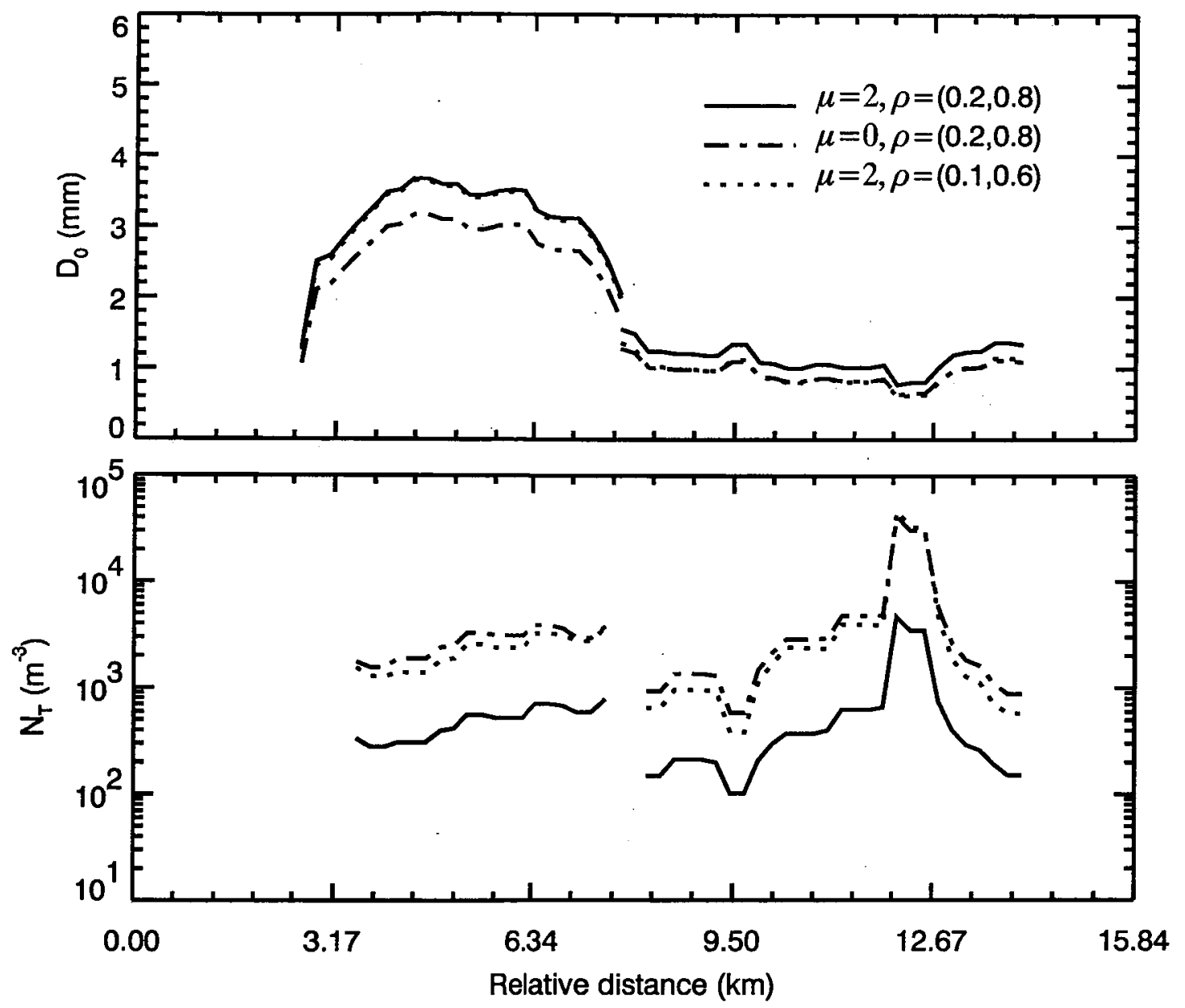

Fig.11 Comparisons of $\mathrm{D}_{0}$ (top) and $\mathrm{N}_{\mathrm{T}}$ (bottom) retrieved from the data of the $\mathrm{T}-39$ radar shown in Fig.6a and $6 \mathrm{~b}$ at the different $\mu$ and the combinations of the snow densities. For example, the combination of the snow densities, $\rho=(0.1,0.6)$, stands for the snow densities of $0.1 \mathrm{~g} / \mathrm{cm}^{3}$ for aggregates and $0.6 \mathrm{~g} / \mathrm{cm}^{3}$ for graupel, respectively. 

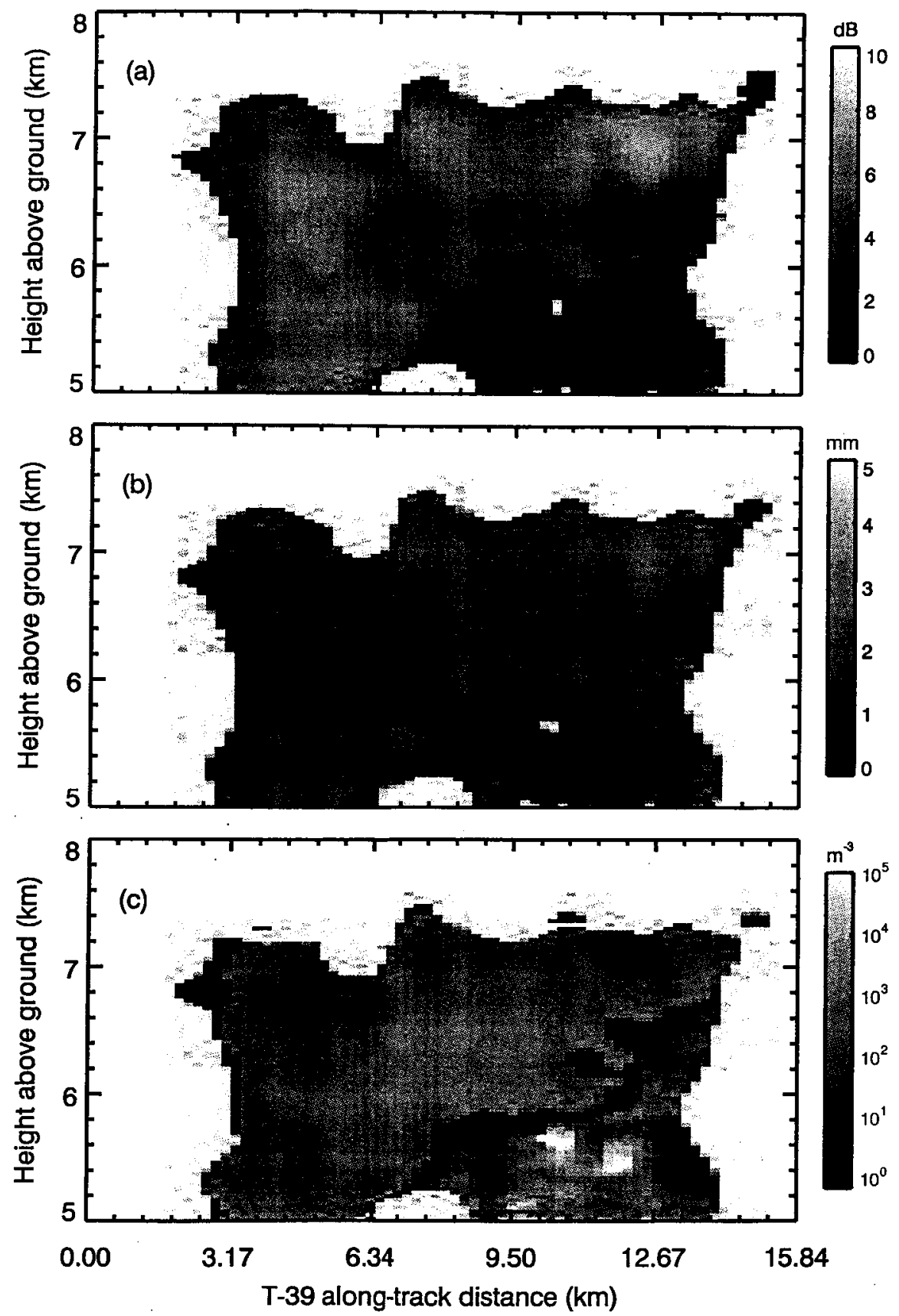

Fig.12 Maps of $\mathrm{D}_{0}$ and $\mathrm{N}_{\mathrm{T}}$ derived from the T-39 radar measurements, as shown in Fig.6a, within the snow region where the altitude of radar echoes is greater than $5 \mathrm{~km}$ above the surface: (a) measured DFR of $X$ and Ka bands, (b) $D_{0}$ in $\mathrm{mm}$ and (c) $\mathrm{N}_{\mathrm{T}}$ in $\mathrm{m}^{-3}$. 


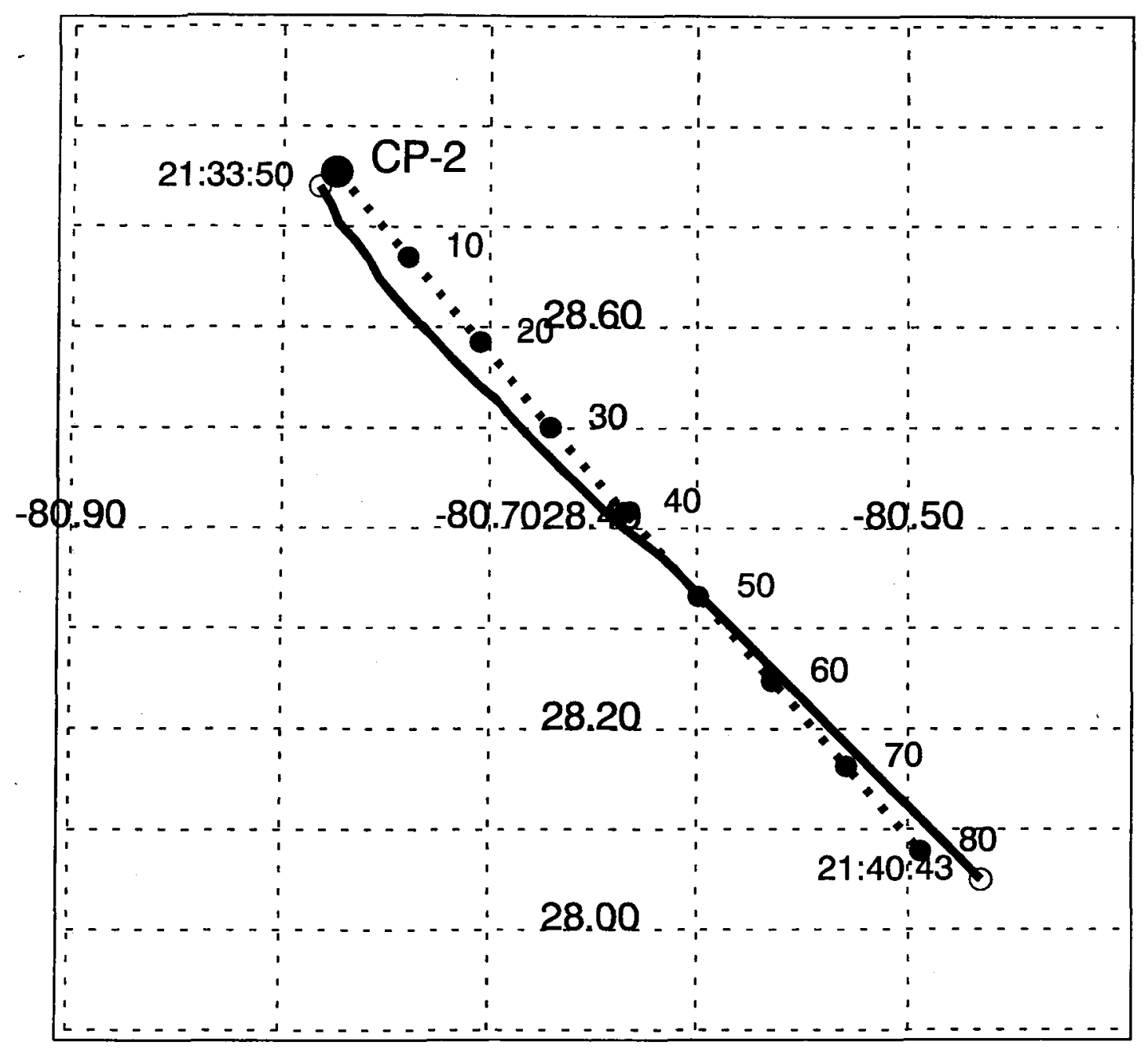

Fig.13 Map of the T-39 flight track (solid line) in reference to the NCAR CP-2 radar. The dashed line represents direction along which the RHI scan of the CP-2 was taken. Distances in $\mathrm{km}$ from the $\mathrm{CP}-2$ are shown along the dashed line. 


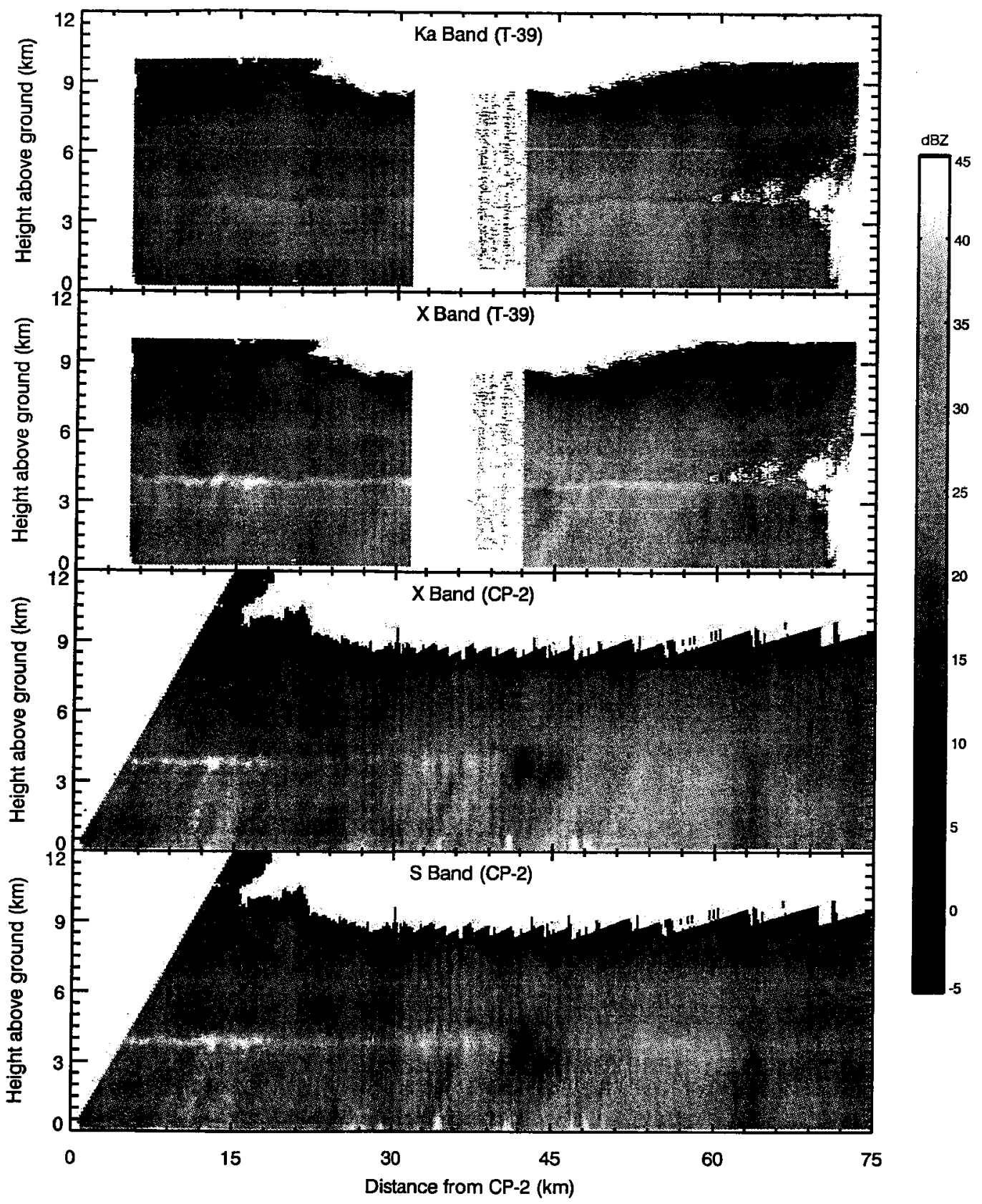

Fig.14 Radar measured reflectivity factors of the T-39 airborne radar (top two images) and the CP-2 ground radar (bottom two images) in terms of the distance from the CP-2. The data are the measurements corresponding to the T-39 flight track and the CP-2 RHI scan, shown as the solid and dashed lines in Fig. 13, respectively. 

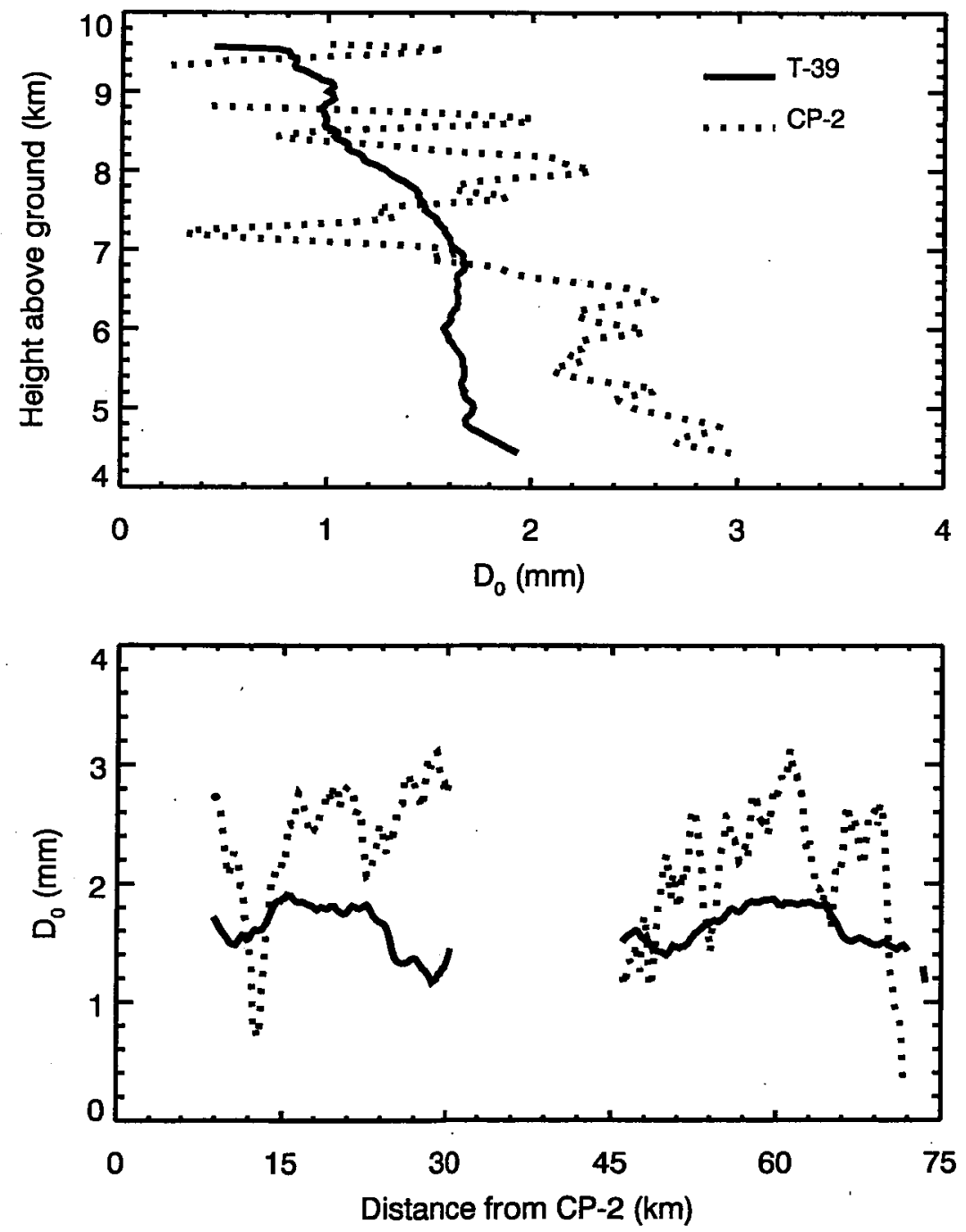

Fig.15 Comparisons of the vertical (top) and horizontal (bottom) profiles of $\mathrm{D}_{0}$ as derived from the T-39 airborne and CP-2 ground-based radars in the snow region. 